\title{
Beiträge zur Kenntniss der Anatomie der Cestoden.
}

$$
\text { Von }
$$

\section{Dr. H. Griesbach,}

Privatdocent an der Universität Basel.

Hierzu Tafel XXI, XXII, XXIII und 1 Holzschnitt.

Ich beabsichtige in Nachstehendem die Resultate einiger Untersuchungen ïber den feineren anatomischen Bau eines Cestoden mitzutheilen, dessen Aufenthaltsort der Darm der Riesenschlange ist.

Der Parasit führt den Namen Solenophorus megalocephalus. Das Untersuchungsmaterial erhielt ich durch die Güte des Herrn Prof. Dr. Bïtschli in Heidelberg, dem ich hier nochmals meinen Dank dafür ausspreche.

Schon früher mit Cestodenstudien beschäftigt, kam mir die Anregung zu dieser Arbeit durch den kürzlich erschienenen Aufsatz von von Roboz ${ }^{1}$ ). In wiefern meine Untersuchungen mit denen dieses Forschers tibereinstimmen, in wiefern sie von denselben abweichen, wird im Verlaufe der Arbeit sich zeigen.

Wenn es sich darum handelt die Anatomie eines Bandwurmes kennen zu lernen, so ist es nothwendig, folgende Punkte zur Untersuchung heranzuziehen: 1) Die Grundsubstanz (Körperparenchym), 2) die sogenannte Cuticula und die subcuticularen Schichten, 3) das sogenannte Wassergefässsystem, 4) die Kalkablagerungen, 5) die Muskulatur, 6) das Nervensystem, 7) die Geschlechtsorgane. Die letzteren Organe werden in dieser Arbeit nicht berücksichtigt werden.

Ich beginne mit der :

1) Zoltán von Roboz: Beiträge zur Kenntniss der Cestoden. Zeitschrift für wiss. Zoologie Bd. XXXVII. H. 2p. 263 bis 285. 


\section{Grundsubstanz.}

Mit Rücksicht darauf, dass die Grundsubstanz (Körperparenchym) des Cestodenleibes iberall die gleiche Beschaffenheit zeigt, kann ich, übereinstimmend mit $v$ o n Robo ${ }^{1}$ ) einer künstlichen Unterscheidung des Leibesparenchyms in Rinden- und Mittelschicht ${ }^{2}$ ) nicht das Wort reden.

Diese Eintheilung kann gar leicht auf den Gedanken fithren, dass wir es in den erwähnten 2 Regionen morphologisch mit verschiedenen Dingen zu thun hätten, während ihr in Wirklichkeit höchstens ein praktischer Werth zugeschrieben werden kann. So weit ich die einschlägige Literatur ubersehe, wird die Grundsubstanz des Cestodenkörpers von den meisten Forschern, welche dieselhe einer Untersuchung unterzogen haben, schlechthin als Bindegewebe (Sommer und Landoi ${ }^{3}$ ) mit den Zusätzen: einfach zellig (Stied ${ }^{4}$ ), einfach hyalin (R. Leuckart ${ }^{5}$ ), fibrillär (v. Roboz") bezeichnet. Schneider ${ }^{7}$ ) lässt die Grundsubstanz aus einem diffusen körnigen Protoplasma bestehen, in welchem die Organe eingebettet liegen, eine nähere Untersuchung über die Organisation dieser Substanz scheint nach ihm an der Unvollkommenheit unserer Untersuchungsmethoden zu scheitern.

Schiefferdecker ${ }^{3}$ ) lisst das Körperparenchym aus einem „eigenthümlichen“ Bindegewebe bestehen, dessen Eigenschaften sich besser an älteren als an jüngeren Gliedern studiren lassen. In den älteren Proglottiden findet man ein zierliches Intercellular-

1) von Roboz, l. c. p. 268.

2) Zuerst von Eschricht mit diesem Namen belegt: Nova Acta Acad. C. L. Vol. XIX. Supplem.

3) Sommer und Landois, Ueber den Bau der geschlechtsreifen Glieder von Bothriocephalus latus. Zeitschr. f. wissenschaftl. Zoologie Bd. XXII. H. 1. p. 44.

4) Stieda, Ein Beitrag zur Anatomie des Bothriocephalus latus. Arch. f. Anat. und Physiol. und wisseuschaftl. Medicin 1864. p. 180, wo übrigens das Wort „Bindesubstanz" gebraucht wird.

5) R. Leuckart, Parasiten. Bd. I. p. 354.

6) von Roboz, l. c. p. 209.

7) Schneider, Untersuchungen über Plathelminthen. XIV. Bericht der oberhessischen Gesellschaft für Natur- und Heilkunde. Giessen 1873. p. 76.

8) Schiefferdecker, Beiträge zur Kenntniss des feineren Baues der Tänien. Jen. Zeitschr. f. Naturw. Bd. VIII. H. 1 p. 467 sq. 
netz, das aus verschieden gestalteten Bälkchen gebildet wird, die ein Netzwerk in dem ganzen Gliede bis zur Cuticula reichend bilden. In den Netzmassen ,liegen oder lagen (falls sie zu Grunde gegangen sind) die Bindegewebszellen, welche die Bälkchen ausscheiden." Nach Salensky") besteht das Körperparenchym von Amphilina aus einem Zellennetz (p. 297 und 333), auch nennt er es ein Gewebe von „durchlöchertem, spongiösen Character" (p. 303).

Auf Grund eigener Beobachtungen muss ich denjenigen von diesen Ansichten, nach welchen die Grundsubstanz der Cestoden den Namen Bindegewebe erhält, entgegentreten. Die Grundsubstanz genannter Würmer ist nach meinen Untersuchungen an Solenophorus kein Bindegewebe, sondern ich finde vielmehr, dass dieselbe grosse Aehnlichkeit mit der Bindesubstanz der Mollusken, insbesondere der Acephalen, besitzt.

In meiner Arbeit über das Gefässsystem und die Wasseranfnabme bei den Najaden und Mytiliden ${ }^{2}$ ) habe ich mich binsichtlich der Bindesubstanzfrage den Ansichten Kollmanns ${ }^{3}$ ) angeschlossen. Fortgesetzte Untersuchungen uber diesen Gegenstand haben mich in der Beipflichtung der Kollmann'schen Ansichten nur bestärkt.

Meiner Meinung nach haben wir es in der Körpersubstanz der Cestoden, wie in der der Acephalen mit embryonaler Gewebesubstanz, welche von Kollmann als Gallertgewebe bezeichnet wird, zu thun, in welchem die einzelnen Organe, zum Theil von struc turlose n Me mbranen, den Abkömmlingen desselben, umgeben, eingebettet liegen.

Histologiseh, physikalisch und chemisch ähnelt das Körperparenchym unserer Würmer dem Gallertgewebe der Acephalen auffallend. Wenn das Gallertgewebe ${ }^{4}$ ) sowohl ontogenetisch als auch phylogenetisch der gemeinsame Boden ist, auf welchem die verschiedenen Formen der Bindesubstanzen sich aufbauen, so er-

1) Salensky, Ueber den Bau und die Entwicklungsgeschichte der A mphilina. Zeitschr. f. wissenschaftl. Zoologie. Bd. XXIV. 1874.

2) Griesbach, Ueber das Gefässsystem und die Wasseraufnahme bei den Najaden und Myliliden. Zeitschr. f. wissenschaftl. Zool. Bd. XXXVIII, auch besonders als Habilitationsschrift gedruckt.

3) Kollmann, Die Bindesubstanz der Acephalen. Arch. f. mikrosk. Anat. Bd. XIII. Häutchenzelle und Myxom. Virchow's Arch. Bd. LXVIII. Structnrlose Membranen bei Wirbelthieren und Wirbellosen. Sitzungsb. d. math.-phys. Kl. d. k. bayr. Acad. d. W. 1876. H. II.

4) Kollmann, Structurlose Membranen bei Wirbelthieren und Wirbellosen. p. 184. 
scheint es nicht wunderbar, wenn es Organismen gibt; bei welchen es bis zu einer subtilen Gewebsdifferenzirung nicht kommt, sondern bei denen das primitive Gewebe zeitlebens, und zwar nicht nur auf gewisse Organe beschränkt, sondern als Grundsubstanz des Leibes persistirt ${ }^{1}$ ).

Das Körpergewebe von Solenophorus zeigt in der That eine äusserst geringe Differenzirung und repräsentirt eine embryonale Form. Da gibt es keine grosse, äusserst zahlreiche, rundliche oder ovale Zellen, wie Sommer und Landois') bei Bothriocephalus beschreiben und abbilden, da gibt es keine Bindegewebsfibrillen im Sinne des Histologen, wie von $\mathrm{Roboz}^{3}$ ) angibt.

Dass Schneider's ${ }^{4}$ ) Angaben, nach welchen das Körperparenchym der Cestoden nicht aus gewöhnlichem Bindegewebe besteht, von späteren Beobachtern nicht mehr beriicksichtigt und einer eingehenderen Prüfung unterzogen worden sind, muss um so mehr Wunder nehmen, als aus seiner Beschreibung hervorgeht, dass man es in dem betreffenden Falle keineswegs mit gewöhnlichen Organisationsverhältnissen zu thun hat. Schneider sagt (p. 76), der ganze Körper der Cestoden sei von Protoplasma gegebildet, welches eine feinkörnige Beschaffenheit zeige, und Kerne enthalte, die bei einigen Cestoden reichlich, bei anderen sparsam vorkämen. Er widerspricht auch Sommer's und La ndois' Angaben uber die Zellenstrulktur des Körperparenchyms und sagt: „Was die runden Stellen (womit Sommer's und Land o is' Rundzellen gemeint sind) in der Mitte des Körpers betrifft, so finden sie sich in der Halsgegend noch nicht. Weiter nach hinten sieht man in dem Protoplasma zuerst einzelne belle Rüume auftreten, die sich in den reifen Gliedern stark vermehrt haben, so dass das ibrige Protoplasma nur dünne Wände zwischen ihnen bildet. Von Protoplasma sind die Räume sicher nicht erfüllt, sondern von Fliissigkeit. Wären sie·Zellen, so müsste man folglich die Kerne an der Wand der Zelle sitzen sehen. Dies ist mir aber nie gelungen, die Kerne

1) Dass Gallertgewebe selbst bei Wirbelthieren und auch beim Menschen, wenn auch in geringer Ausdehnung so doch im ganzen Körper existirt, ergibt sich aus den Untersuchungen Kollmann's, Häutchenzelle und Myxom. p. 30 .

2) Sommer und Landois l. c. p. 44.

3) v. Roboz l. c. p. 269.

4) Schneider 1. c. p. 76 und 77 . 
liegen vielmehr in der festen Substanz zwischen den Räumen. Nitunter scheint allerdings ein Kern in der Mitte der Zelle zu stehen, dann ist man aber nicht sicher, dass er in einem darunter liegenden Stücke fester: Substanz sich befindet." Diese Angaben muss ich im Allgemeinen für Solenophorus bestätigen.

Vom Scolex bis zur letzten Proglottide besteht das Körperparenchym aus einer sehr fein granulirten Substanz (Fig. 1, 2, 3, $11,15,23,25 \mathrm{ggw}$, die gewischten Stellen), die Protoplasma gleicht, nur dass sie eine bedeutendere Festigkeit besitzt. Wenn diejenigen Gewebeformen, welche man schlechthin als Bindegewebe bezeichnet, unter so wechselnden Gestalten auftreten, dass sich allgemeine Charaktere oft bis zur Unkenntlichkeit verwischen, so kann ich in diesem Verhalten doch keine Entschuldigung dafiir erblicken, dass das Gros der modernen Histologen jedwede Bindesubstanz mit dem Namen Bindegewebe belegt. Mögen die Formen des letzteren noch so verschieden sein, immer werden sie histogenetisch doch einem mehr oder minder weit vorgesehrittenen Differenzirungsprozess, dem eine primäre Substanz, eine Muttersubstanz zn Grunde liegt, ibre Entstehung verdanken, eine Deutung, welche durch pathologische Neubildungen oder regressive Gewebsveränderungen natïrlich keine Beeinträchtigung erfahren kann. Unter den beim Menschen vorkommenden Tumoren bestehen die als Myxome bezeichneten bekanntlich aus Gallertgewebe ${ }^{1}$ ), mit fortschreitender Differenzirung gesellen sich den Gewebsformen secundäre histologische, physikalische, chemische, physiologische Eigenschaften hinzu, welche der Muttersubstanz fremd waren. Unter diesen Gesichtspunkten ist jedwedes Bindegewebe nur eine weitere Entwicklungsform einer Muttersubstanz $\varkappa \alpha \tau \grave{c} \xi \alpha \chi \eta \nu$ und diese ist das Gallertgewebe. Dafür spricht auch der Umstand, dass selbst im reifen Bindegewebe sich gelegentlich noch ursprünglich dem Gallertgewebe angehörige Zellformen finden. Dahin dürften wohl die "grossen, mehr rundlichen protoplasmareichen Zellen" zu rechnen

1) In die Pathologie ist das Gallertgewebe (Schleimgewebe) durch Virchow (Cellularpathologie 4. Auft. p. 40. Krankheiten der Geschwülste. Bd. I. p. 397) eingeführt. Später hat es vielfache Anfechtungen erlitten und schliesslich wurden ihm von Köster (Sitzungsber. d. niederrhein. Gesellschaft. Bonn 17. Januar 1881), Rumler (Ueber Myxom und Schleimgewebe. Inaug.Dissert. Bonn 1881) und Clementz (Ueber das Schleimgewebe in Parotisgeschwülsten. Inaug.-Dissert. Bonn 1882) die Berechtigung bestritten. 
sein, welche durch Waldeyer $\left.{ }^{1}\right)$ beschrieben worden sind. Gewisse Zellgruppen des Hodens und vielleicht auch die sogenannten Parenchymzellen der Nebenniere gehören dazu.

Was von Michalcovics als Endothelzellen beschreibt und abbildet ${ }^{2}$ ) dürfte als Rest des Gallertgewebes aufzufassen sein.

Dieses Gallertgewebe kann bei Wirbellosen entweder eine völlig structurlose Masse sein, oder es treten verschiedene Zellformen in ihm auf. Die wesentlichsten Punkte, in welchen es sich von Bindegewebe unterscheidet, sind: Es besitzt einen relativ höleren Grad von Derbheit, es besitzt ein grösseres, oft von Interferenzerscheinungen begleitetes Lichtbrechungsvermögen, es ist resistent gegen Säuren und liefert keinen Leim. Durch die klassischen Untersuchnngen Kollmann's ist das Wesen und die Bedeutung des Gallertgewebes neuerdings ins rechte Licht gesetzt worden und es wird in der sogenannten Bindegewebsfrage jetzt seine Rolle spielen. Früher schon ist von Virchow ${ }^{3}$ ) und Schultze ${ }^{4}$ ) nachgewiesen, dass die Körpermasse der Acalephen zum grossen Theil daraus besteht. Gewiss ist es namentlich bei Wirbellosen viel mehr verbreitet als man bisher geglaubt und weitere Untersuchungen werden dies festzustellen haben. Im Körper der Cestoden ist es die einzigste Bindesubstanz und zwar finde ich darin die zelligen Elemente, wie sie von Kollmann und mir im Acephalenleibe beschrieben worden sind, nur zum Theil wieder. Dagegen gibt es wie bei den Acephalen Gewebsläcken in Form von oftmals mit einander anastomosirenden Lakunen (Fig. 1, 2, 3, 41), welche einer selbstständigen Wandung ermangeln, in deren Umgebung aber das structurlose Gewebe eine Grenzschicht bildet, die, wenn auch nur in geringem Grade resistenter als die iibrige Gallertmasse, namentlich bei Behandlung mit Ueberosmiumsäure deutlich hervortritt (Fig. 3stml u. 5).

Schon Schneider hat, wie erwähnt, diese "hellen Räume" gesehen und die Angaben Sommer's und Land ois', dass dieselben Zellen seien, zuriickgewiesen. Wer näher das Gallertgewebe der

1) W a ld e y e r, Ueber Bindegewebsz ellen. Arch. f. mikroscop. Anat. XI. p. 189.

2) v. Michalcovics, Beiträge zur Anatomie und Histologie des Hodens in Arbeiten aus der physiol. Anstalt zu Leipzig, mitgetheilt von C. Ludwig 1874. Taf. III. Fig. 8.

3) Virchow, in seinem Archiv Bd. VII. p. 558.

4) Schultze, Müller's Archiv 1856 p. 311. 
Mollusken untersucht hat ${ }^{1}$ ), der wird an die Zellennatur dieser Gebilde bei Cestoden auf den ersten Blick nicht glauben. Typische Kerne finden sich nicht darin, sondern dieselben liegen in den Gallertbalken. Auf dem Schnitt ereignet es sich oft, dass man durch die Lakune das tiefer liegende Gewebe durchscheinen sieht, wobei dann ein Bild entstehen kann, nach welchem es scheint, als enthalte der blasige Hohlraum einen als wesentlichen Bestandtheil zu ihm gehörenden Kern, de facto aber befindet sich dieser tiefer in der Gallertsubstanz, oder er ist, wie wir es später sehen werden, ganz anderer Herkunft, Diese eben genannten Kerne sind überall in dem Gewebe verbreitet, wenn auch in der sogenannten Mittelschicht nicht ganz so zahlreich als in der Rindenschicht. Hänatoxylin, Jodgrün und andere brauchbare Kerntinctionsmittel färben dieselben intensiv (Fig. $1 \mathrm{k}$ ) ; die Grundsubstanz selbst nimmt Farbstoffe nur schwierig an, die einzigsten, mit denen ich eine, wenngleich schwache, oft diffuse Färbung erhielt, waren Azofarbstoffe ${ }^{2}$ ) und Rose bengale ${ }^{3}$ ).

Die Kerne der Mittelschicht liegen bald - wenigstens finde ich mit aller Mtihe kein Protoplasma - isolirt4) (Fig. 1k), bald häuft sich eine geringe feinkörnige Protoplasmamasse darum (Fig. $1 \mathrm{k}_{1}$ ), der eine Zellmembran positiv fehlt. Die Plasmamasse ist wegen ihrer ausserordentlichen Feinheit überhaupt oft schwer wahrnehmbar. Ueberosmiumsäure lässt sie etwas dentlicher hervortreten, während eine Zellcontour damit auch nicht darzustellen ist. Diese plasmatischen Zellen sind meist kagelig und zeigen keine Ausläufer. Ausser ihnen finden sich noch glashelle, geschlängelte, wie Spirillen aussehende Fädchen (Fig. $3 \mathrm{~g} \mathrm{fb}$, Fig. $6 \mathrm{~b}$ ) in der Bindesubstanz eingesprengt, sie liegen isolirt, sind von stark lichtbrechen-

1) Auch die von Kollmann und mir als Lakunen beschriebenen Gewebslücken der Acephalen werden von Flemming (Ueber Bindesubstanzen und Gefässwandung bei Mollusken. Habilitationsschrift. Rostock 1871 und Ueber Bindesubstanz und Gefässwandung im Schwellgewebe der Muscheln. Arch. f. mikr. Anat. Bd. XIII) für Zellen gehalten.

2) Griesbach, Die Azofarbstoffe als Tinktionsmittel für menschliche und thierische Gewebe. Diese Zeitschr. Bd. XXII. H. 1.

3) Griesbach, Beiträge zur Verwendung von Anilinfarbstoffen in der mikroskopischen Technik. Zoolog. Anzeiger Nr. 135 (1883).

4) Ueber ,nackte Kerne" vergl. übrigens Stricker, Beobachtungen über die Entstehung des Zellkernes. Sitzungsber. d. Wien. Acad. math.-nat. Cl. Bd. 76. H. 77. 7. Juni. 
der Kraft, nur mit scharfen Systemen wahrzunehmen und schon von Kollmann als Gallertfibrillen bei Mollusken beschrieben.

Spindelzellen mit zwei oder mehreren Ausläufern, wie sie im Gallertgewebe der Mollusken vorkommen, finden sich ebenfalls (Fig. 3sp z. Fig 6a). Ihr Plasmaleib ohne Fortsätze misst an Alkoholpräparaten, wenn man im Allgemeinen die Grösse angeben will, 0,0144 $\mathrm{mm}$ und der Kern 0,02 mm. Die grossen Rundzellen fehlen - nur auf der Grenze der Wassergefässhauptstränge finden sich eigenthümliche Zellen als Bestandtheil des Gallertgewebes, doch von ihnen später. Pigment, welches im Gallertgewebe der Mollusken vielfach vorkommt, konnte ich bei Cestoden ebenfalls wahrnehmen; namentlich ist dieses bei Solenophorus im Scolex und in den Proglottiden dicht unter der Cuticula verbreitet. Was die Gewebslakunen anbelangt, so kann man eine bestimmte Grössenangabe nicht machen. Im Allgemeinen sind dieselben im Scolex und in den Anfangsgliedern der Strobila kleiner als in den geschlechtsreifen Proglottiden. Man findet gelegentlich in ibnen als anch iiberall im Gallertgewebe, in der Rindensehicht an Zahl zunehmend, Kalkconcremente verbreitet, doch werde ich Näheres ïber diese sowie ïber die Lakunen selbst erst bei dem Wassergefässsystem beibringen.

Wenn nun die Bindesubstanz der Cestoden Gallertgewebe ist, dann wird sich dieses auch auf der Grenzschichte der Organe wiederfinden und dieselben mit einem durch Verdichtung des Gallertgewebes entstandenen structurlosen Häntchen umgeben. Die Entstehung solcher structurloser Membranen aus dem Gallertgewebe, welches "structurlos ist per se“, wurde durcb Kollmann's Untersuchungen bei Acephalen über allen Zweifel gestellt.

An diesem Punkte angelangt kann ich die Frage nach der Stellung der Zellen zur Intercellularsubstanz nicht unberiicksichtigt lassen. Bekanntlich stehen sich in der sogenannten Bindegewebsfrage zwei Parteien schroff gegenüber. Die einen, namentlich Schwann ${ }^{1}$, Valentin ${ }^{2}$, Max Schultze ${ }^{3}$, Babuchin ${ }^{4}$, Kutz-

1) Schwann, Mikroskopische Untersuchungen über die Uebereinstimmung in der Structur der Thiere und der Pflanzen. 1839. p. 135.

2) Valentin, Artikel: Gewebe in R. Wagner's Handwörterbuch der Physiologie. 1842. Vol. 1 p. 670.

3) M. Schultze, in Reichert's u. du Bois-Reymond's Arch. 1861.p. 18.

4) Babuchin, in Stricker's Handbuch der Gewebelehre. p. 67 A. 1. 
netzoff ${ }^{1}$ ), Ober steiner ${ }^{2}$ ), Boll $\left.{ }^{3}\right)$, O. Hertwig ${ }^{4}$ ) und neuerdings manche andere Forscher schreiben jeglichen formativen Prozess in der Bindesubstanz den Zellen zu; die anderen, Hen $1 \mathrm{e}^{5}$ ), Vi rch ow ${ }^{6}$ ), Reicherti $)$, Donders ${ }^{8}$ ), Müller ${ }^{9}$ ), Kölliker ${ }^{10}$ ), Leydig ${ }^{11}$ ), Frey ${ }^{12}$ ), Rollet ${ }^{13}$ ), Babl Rückhard ${ }^{14}$ ) verlegen die Bildungen von elastischen Fasern in die Intercellularsubstanz.

In nenster Zeit lässt Kollmann ${ }^{15}$ ) die Intercellularsubstanz noch weiter thätig eingreifen; sie ist nicht todte Masse, sondern ist chemischer und physikalischer Umwandlungsprocesse fähig und spielt bei der Histogenese eine wichtige Rolle $\left.{ }^{16}\right)$. Eine wesentliche

1) Kutznetzoff, Wiener Sitzungsberichte Bd. 56. Abth. 2. p. 162.

2) Obersteiner, daselbst S. 251 .

3) Boll, Untersuchungen über den Bau und die Entwicklung der Gewebe. Berlin 1871. p. $28 \mathrm{ff}$. und Arch. f. mikr. Anat. Bu. VIII. 1872. p. 61.

4) 0. Hertwig, Ueber die Entwicklung und den Bau des elastischen Gewebes im Netzknorpel. Arch. f. mikr. A nat. Bd. IX. 1873. p. 80 u. Taf. VII.

5) Henle, Handbuch der system. Anat. des Menschen. Eingeweidelehre. Braunschweig 1866. p. 617 Anm.

6) Virchow, Ueber die Identität von Knochen-Knorpel und Bindegewebskörperchen, sowie über dic Schleimgewebe. Würzb. medic. Verhandl. 1852. II. p. 150 u. in: Weitere Beiträge zur Structur der Gewebe der Bindesubstanz. I. Bd. p. 314.

7) Reichert, Bemerkungen zur vergleichonden Naturforschung und vergleichende Beobachtungen über Bindegewebe und die verwandten Gebilde. Dorpat 1845. - id. Zur Streitfrage über die Gebilde der Bindesubstanz, über die Spiralfaser und über den Primordialschädelin Müller's Arch. 1852. p. 511.

8) Donders, Form, Mischung und Function der elementaren Gewebstheile ctc. Zeitschr. f. wissensch. Zoologie. 1851. Bd. IlI. p. 354.

9) H. Müller, Würzb. Verhandl. Vol, X. p. 132.

10) Kölliker, Neue Untersuchungen über die Entwicklung des Bindegewebes. Würzburg 1861.

11) Leydig, Histologie des Menschen. Frankfurt a. M. 1857. p. 24 u. 27

12) Frey, Handbuch der Histologie und Histochemie. Leipzig, Engelmann 1874. p. 243 und 244.

13) A. Rollett, Von den Bindesubstanzen in Stricker's Handbuch p. 63 u. $\mathrm{ff}$.

14) Rabl Rückhard, Müller's Archiv 1863. p. 41.

15) Kollmann, Häutchenzelle u. Myxom. Virchow's Arch. Bd. LXVIII. - id. Structurlose Membranen bei Wirbelthieren und Wirbellosen. Sitzungsberichte d. mathem.-physikal. Ges. d. k. bayr. Acad. d.Wissensch 1876. H. 2. - id. die Bindesubstanz der Acephalen.

16) Fle m m ing (Zellsubstanz, Kern u. Zelltheilung mit 24 Textbildern 
Stiitze findet diese Ansicht in der Entdeckung der „Häutchen “1). Auch der gute Klang des Namen Ranvier ${ }^{2}$ ) muss bei dieser Ansicht berücksichtigt werden. Während Kollmann's Beobachtungen sich namentlich auf Wirbellose beziehen, gehören Ranvier's Untersuchungen den Wirbelthiergeweben an. In künstlicher Oedemen aus der Haut eines Rindsembryo von 15 bis 20 ctm. sieht Ran. vier die Fasern unabhängig von den Protoplasmafortsätzen der Zellen entstehen, ähnliche Beobachtungen lassen sich am Rippenknorpel des Menschen, an der Achillessehne eines neugeborenen Kaninchens und an vielen anderen Objecten machen. Auch für elastische Fasern bat Ranvier den gleichen Ursprung nachgewiesen.

Die Kollmann'schen Ansichten sind, so viel mir aus einer mündlichen Mittheilung desselben bekannt, ganz unabhängig von Ranvier und ausserdem wobl firiher entstanden.

Auch Ray-Lankaster ${ }^{3}$ ) hat mit seinen ,ectoplastic and entoplastic tissues" ähnliche Beobachtungen gemacht, doch scheint er mir mit dern "grossblasigen Bindegewebe" bei Mollusken (p. 309 Zeile 2 bis 4) in grossem Irrthum. Wie schon für die Acephalen, so muss ich mich auch jetzt für die Cestoden den zuletzt erörterten Anschaunngen, dass die Intercellularsubstanz, welche sich in reichlicher Menge im ganzen Cestodenleibe findet ${ }^{4}$ ), physiologisch thätig eingreift, anschliessen. Ich lege auf diesen Punkt Gewicht. Hier bildet das Gallertgewebe, ohne "Auswachsen von Zellfortsätzen" überhaupt ohne Hülfe des Zellprotoplasmas Gallertfibrillen, structurlose Membranen, elastische Fasern, ja und als Gemisch der beiden letzteren - eine ganze Cuticula.

Allerdings wenn ein so eifriger Verfechter der Max Schultze-

und 8 Tafeln. Leipzig, Vogel 1882) der eigentlich diese Anschauungen nicht theilt, findet neuerdings (p. $83 \mathrm{Anm}$.) doch ein, dass neine blosse A bweis ang dieser Ansicht nicht gestattet ist."

1) Vergl. die Literatur bei Kollmann l. l. c. c.

2) Ranvier, Technisches Lehrbuch der Histologie (aibersetat von Nicati und Wyss). Leipzig, Vogel 1877. p. 378-379.

3) Ray-Lankaster, On the connective and vasifactive tissues of the medicinal I eech in Quarterly Journal of microscopical science Vol. XX, new series. 1880.

4) Für die älteren Proglottiden behauptet Moniez, Mémoires sur les Cestodes (Travaux de l'institut zoologique de Lille. Paris 1881): „il n'y a pas trace de substance intercellulaire." 
schen Bindegewebstheorie wie Boll ${ }^{1}$ ), alles, was inter cellulas liegt, für „Zellenleib“ erklärt, dann bört der Begriff Intercellularsubstanz und somit auch jedwede Function, welche derselben zufiele, gänzlich auf, die Unhaltbarkeit einer solchen Deutung, wie sie schon Rolett ${ }^{2}$ ) dargethan, glaube ich, braucht heute nicht mehr betont zu werden. Neuerdings spricht $\mathrm{Brock}^{3}$ ) in einer vorläufigen Mittheilung die Meinung aus, dass Fibrillen in der fibrillären Bindesubstanz bei Mollusken (speziell Aplysia) aus Zellen hervorgehen. Nach meinen Untersuchungen muss ich diesen Aussagen entscbiedenen Widerspruch entgegensetzen. Uebrigens scheint Brock die neueren Arbeiten iaber Bindesubstanz bei Mollusken namentlich die Kollmann's; nicht zu kennen, der ganze Streit zwischen Kollman n und Fl e mming scheint ihm entgangen, wenigstens werden deren Arbeiten mit keinem Worte Erwähnung gethan, ja nach ihm soll alles, was wir über homogene Bindesubstanz bei Mollusken wissen, sich auf einige kurze Notizen von Leydig und Semper beschränken.

Von den Gebilden, welche als Abkömmlinge des Gallertgewebes in dem Cestodenleibe vorkommen, beschäftigen uns vor allen die Körperwand, die sogenannte

\section{Cnticula, und die subeuticularen Sehichten,}

deren Bau und Bildung lange Zeit Gegenstand eifriger Controversen gewesen sind. Bei Solenophorus ist sie nach meinen Untersuchungen eine nicht ïberall gleich starke, an den Bothridien am wenigsten mächtig entwickelte, helle, zwischen $0,013 \mathrm{~mm}$ und 0,005 mm Dicke schwankende Membran (Fig. 1, 2, 4, 7, 8, 9m). J. P. van Benedent) sagt: „La pean se sépare facilement en derme ou chorion et en épiderme. Ce dernier consiste toujours dans une pellicule mince, transparente, généralement lisse, sans soies ni cils. Il a partout à peu près la même épaisseur. Le chorion que l'on peut souvent séparer avec facilité, est assez épais et

1) Boll, Untersuchungen über den Bau und die Entwicklung der Gewebe. Arch. f. mikr. Anat. Bd. VIII. p. 61.

2) Rol et.t, Ueber die Entwicklung des fibrillären Bindegewebes. Untersuchungen aus dem Institute fïr Physiologie und Histologie in Graz. 3. H. p. $257-265$.

3) Brock, Ueber homogene und fibrilläre Bindesubstanz bei Mollusken. Zool. Anzeiger Nr. 124.

4) J. P. van Beneden, Sur les vers cestoides. Mémoires de l'académie royale etc. T. XXV. Bruxelles 1880. p. 31. 
montre des fibres entre-croisées, comme feutrées." Die Epidermis und das Chorion van Beneden's werden wohl die beiden Schichten sein, welche Steudener ${ }^{1}$ ) beschreibt, und die auch ich bei Solenophorus finde (Fig. 1, 2, $7 \mathrm{~m}$ u. $\mathrm{m}_{\text {, }}$ ).

Die untere Schicht besteht aus, in dem Breitendurchmesser des Gliedes verlaufenden, parallelen, unverästelten Fasern. Sie scheinen Sommer's und Landois'2) elastische Fasern zu sein, Schiefferdecker ${ }^{9}$ ) nennt sie Fibrillen. Steudener spricht sich über ihre Natur nicht aus, Kahane $e^{4}$ nennt sie einfach Cuticularfasern, von Roboz ${ }^{5}$ ) giebt ihnen den Namen Bindegewebsfibrillen und R. Le uckart ${ }^{6}$ ) hält sie neuerdings für Muskelfasern, welche mit den darunter liegenden Längsmuskeln den Hautmuskelschlauch der Cestoden bilden. Nach meinen Beobachtungen werden die Fasern mit Alkalien behandelt noch dentlicher, verhalten sich resistent gegen Säuren und sind, wie der ibrige Theil der Cuticula, Bildungen des Gallertgewebes. Ich nenne sie mit Sommer und Lando is elastische Fasern, womit treffend ihre physikalische Beschaffenheit gekennzeichnet wird. Sehr schön sieht man dieselben auf Flächenschnitten (Figr. $10 \mathrm{ef}$ ), wo sie sich mit den subcuticularen Längsmuskelfasern ( $\mathrm{Fin}$. $10 \mathrm{slm}$ ) kreuzen.

Nach aussen zu von dieser Faserschicht findet man die zweite Schicht der Cuticula, welche von ganz structurloser und homogener Beschaffenheit ist.

Zograf ${ }^{7}$ ) und Kahane ${ }^{8}$ ) unterscheiden in der Cuticula drei, Schiefferdecker ${ }^{9}$ ) sogar vier Schichten. Von seiner sogenannten „feinpunctirten" Schicht und „Deckschicht" habe ich nichts finden können. Von den letzteren gla ubt $\mathrm{Sc}$ h i ef fer d e c k er schliesslich selbst,

1) St e u de n er, Untersuchungen über den feineren Bau der Cestoden.

Abh. d. naturf. Gesellschaft zu Halle. Bd. XIII. 1877. p. 283.

2) Sommer u. Landois l. c. p. 42.

3) Schiefferdecker l. c. p. 462 u. 463.

4) Kahane, Anatomie von Taenia perfoliata, als Beitrag zur Kenntniss der Cestoden. Zeitschr. f. wissensch. Zoologie Bd. XXXIV. p. 194.

5) v. Roboz 1. c. p. 265.

6) Le uckart l. c. p. 368 .

7) Der russische Titel kann hier nicht abgedruckt werden, vergl. daher die Literatnr bei Kahane.

8) Ka hane l. c. p. 194 .

9) Schiefferdecker 1. c. p. 462. 
dass sie nur die äusserste durch fremde Einflusse veränderte Lage der darunter liegenden Schicht sei. Von solchen Veränderungen werde ich gleich reden.

Wie alle genannten Beobachter, so finde auch ich bei Solenophorus die sogenannte Cuticula senkrecht zur Längsachse des Körpers von feinen Porenkanälen durchsetzt (Fig $7 \mathrm{pk}$ ). Doch haben mir die feinsten mit dem Mikrotom angefertigten Querschnitte allein nicht die Ueberzeugung, dass die feine Strichelung wirklich Porenkanäle repräsentirt, abgewinnen können. Die dorso-ventralen Muskeln beften sich nämlich, wie auch schon Schiefferdecker ${ }^{1}$ ) genauer beschreibt, mit einer Art von Sehne an die Cuticula. Beim Schneiden ereignet es sich gar häufig, dass das Messer die Muskeln an ihren Anheftungspunkten zerfasert, und man erbält auf dem Querschnitt, namentlich wenn derselbe ein wenig schräg ausfiel, dann das täuschende Bild, als verliefe eine feine Strichelung mehr oder weniger senkrecht zu der elastischen Faserschicht in der Cuticula (Fig. $1 \mathrm{zm}$ ).

Erst wenn man durch diese Verhältnisse mehrfach getäuscht und dadurch mit ihnen bekannt geworden ist, gelingt es leichter, auch die wirklichen Porenkanäle auf dem Qnerschnitte der Cuticula zu Gesichte zu bekommen. Mit Bestimmtheit aber ïberzeugt man sich sofort ron der Anwesenheit derselben, wenn man einen möglicbst dünnen Flächenschnitt anfertigt. Die Porenkanäle erscheinen alsdann als feine ovale oder runde Löchelchen (Fig. $10 \mathrm{pk}$ ), die bald bell, bald dunkel erscheinen, je nach der verschiedenen Einstellung und der Dicke des Schnittes. von Roboz ${ }^{2}$ ) konnte die Angaben von Sommer und Landois, von Schiefferdecker und Steu dener betreffend den Durchtritt von protoplasmatischen Ansläufern subcuticularer Zellen für Solenophorus nicht bestätigen.

Ich habe diesen Punkt mit ganz besonderer Sorgfalt verfolgt, die vortheilhaftesten Behandlungsweisen der Schnitte verwendet, aber mein Suchen nach den „protoplasmatischen Fortsätzen“ war vergeblich. Man sieht solche Gebilde bei Solenophorus nicht in den Porenkanälen, geschweige denn sich über die Cuticula erheben.

J. P. van Beneden erwähnt in seiner angeführten Arbeit $^{3}$ )

1) Schiefferdecker 1. c. p. 463 .

2) v. Roboz 1. c. p. 264 a. 265.

3) van Beneden 1. c. p. 31 . 
Pigmentflecke in der Haut. Er sagt: „Elle (la peau) est blanche dans tous ces vers, à l'exception de la partie inférieure du cou de quelques Tetrarhynques; en effet, cette partie du corps est ronge et quelquefois noire dans certaines espèces, comme par exemple, celle qui est connue sous le nom de Longicollis. Il y a des plaques de pigment rouge dans certains Scolex dont nous parlerons tout à l'heure. Quelques Proglottis qui deviennent noirs ou verdâtres, doivent cette couleur à leurs oeufs."

Auch bei Solenophorus besitzen die äteren Proglottiden eine grau-schwärzliche Farbe; dieselbe rührt wobl her von den grauschwarzen Pigmentmassen, welche sich hart unter der Cuticula in dem Gallertgewebe befinden (Fig. $7 \mathrm{p} \mathrm{g}$ ).

Auch die eigenthümliche Umwandlung der Cuticula, die Zerkltiftung und Abspaltung, welche schon von Roboz ${ }^{1}$ ) beschreibt, muss ich bestätigen (Fig. 4), und es scheint mir der Ausdruck „Häutung“, den R. L euckart ${ }^{2}$ ) dafür giebt, sehr passend. Abgeseben von den abgestossenen Schtippchen und Fetzen (Fig. 4, 7; $10 \mathrm{f}$.), welche die Cuticula-Oberfläche ganz uneben machen, ist dieselbe noch mit allerhand papillenartigen Gebilden, Borsten und Haaren, besetzt (Fig. $7 \mathrm{ca}$ ), die namentlich in der Umgegend des Porus genitalis eine gewisse Mäcltigkeit erlangen (Fig. 7 und Fig. 8ca). Andere Cuticulagebilde, wie Haken etc. am Scolex fehlen bei Solenophorus. Im Allgemeinen nimmt die Cuticula, wie das Gallertgewebe, von dem sie ausgesehieden wird, nur schwierig Farbstoffe an; Azoverbindungen und Rose bengale aber färben auch sie. Behandelt man dünne Schnitte mit Jodgriin, so tritt die interessante Erscheinung ein, dass sich die Cuticula stellenweise oder gauz violett färbt. Es ist dies nicht anders erklärlich, als dass sie Kalksalze enthält, welche, wie ich schon früher $^{3}$ ) besprochen, das Jodgrïn zersetzen.

Schon Moniez ${ }^{4}$ sagt: „... la cuticule présente en même temps de cellules fusiformes entières et des fibres, des corpuscules

1) v. Roboz l. c. p. 264 .

2) R. Le u ckart 1. c. 1881. Bd. I p. 362

3) $\mathrm{Gr}$ i e s b a c h, Ueber das Gefässsystem und die Wasseraufnahme bei den Najaden u. Myliliden. Biol. Centralbl. Bd. II. Nr. 10. - id. Zeitschr. f. wissensch. Zoologie Bd. XXXVIII. - id. Jodgrün als Tinctionsmittel etc. Zool. Anzeiger Nr. 117.

4) Moniezl. c. p. 130 . 
calcaires en un mot, tous les éléments des couches sous jacentes." Und in der That, auf feinen Flächenschnitten sieht man, wie Fig. 10 zeigt, oft Kalkkörperchen, die aus den Lakunen und dem Gallertgewebe dicht unter der Cuticula stammen, und von denen auch wohl Bruchstiicke in den Porenkanälen stecken mögen. Noch mehr als uber die Cuticula ist, namentlich seit der Arbeit von Rindfleiseh${ }^{1}$ ), über die sogenannten subcuticularen Zellenlager gestritten, denen R. Le uckart ${ }^{2}$ ) unter dem Namen „körnerreiche Parenchymschicht" epithelialen Charakter zuschrieb. Nach Rindfleisch ist die Cuticularschicht bindegewebiger, nicht epithelialer Natur.

Sommer und Landois ${ }^{3}$ ) nennen diese Sehicht eine weiche, dunkelkörnige Substanzlage, betrachten sie als Matrix der Cuticula, und lassen sie aus senkrecht zur Cuticula stehenden spindelförmigen Zellkörperchen bestehen, welche, ohne eine Membran zu besitzen, mit ihrem Protoplasma leicht in einander verschwimmen. Diesen Ansichten schliesst sich Schiefferdecker ${ }^{4}$ ) im Allgemeinen an. Sehneider tritt in die Fusstapfen von $R$ ind fleisch und ist nicht der Ansicht, dass in der Subcuticularschicht ein Epithel zu suchen sei. Steudener ${ }^{5}$ ) lässt die Frage nach der Natur der subcuticularen Zellen, die er im Allgemeinen so beschreibt wie seine Vorgänger, offen, da nach ihm darüber nur die Entwicklungsgesehichte Aufschluss geben könne, und Kahan $\mathrm{e}^{6}$ ) glaubt doch auch, in ibnen eine Epithelschicht sehen zu diirfen, deren Derivat die Cuticula ist.

Der letzte, welcher über die subcuticulare Zellschicht Bericht erstattet, ist von Roboz ${ }^{7}$. Derselbe beschreibt sie bei Solenophorus, wenn ich meine gleich genauer zu besprechenden Untersuchungen zum Vergleiche berbeiziehen darf, noch am richtigsten von allen genannten Forschern. Nach ihm erscheinen die Zellen in den verschiedensten und bizarrsten Gestalten mit allerhand Aus-

1) $\mathbf{R}$ ind $\mathrm{fle}$ is $\mathrm{ch}$, Archiv f. mikr. Anat. Bd. I: Zur Histologie der Cestoden. 1865.

2) R. Le u ckart l. c. Bd. I. p. 166.

3) Som mer u. Landois 1. c. p. 44.

4) Schiefferdecker l. c. p. 462.

5) Steudener l. c. p. 285.

6) Kahane l. o. p. 195 .

7) v. Roboz l. c. p. 266 sq. 
läufern, von denen aber keine, wie die meisten anderen Beobachter behaupten, in die Porenkanäle der Cuticula eintreten. Er findet iberall die Bindegewebsnatur dieser Zellen unverkennbar ausgeprägt, glaubt nicht an die Existenz eines Epithels, findet auch den Namen Cuticula eigentlich unpassend, den Namen „Grenzmembran des den ganzen Körper ausfitllenden Bindegewebes" für sachgemässer.

Dass die sogenannte Cuticula, besser Grenzmembran, Körperwand, nicht von einem Epithel gebildet wird, sondern eine dem Gallertgewebe entstammende structurlose Membran ist, habe ich bereits dargethan; dass von einem Bindegewebe im Sinne des Histologen im Körper der Cestoden keine Rede sein kann, ist ebenfalls zur Gentige erwiesen. Was bleibt jetzt noch für die seltsamen Gebilde, welche man unter dem Namen subcuticulare Zellenlager zusammenfasst, übrig?

Ich werde zunächst den thatsächlichen Befund meiner Beobachtungen mittheilen. Bringt man einen sehr feinen Querschnitt durch eine Proglottide auf wenige Secunden in eine Jodgrünlösung, so findet man nach Fertigstellung des Präparates sämmtliche zum Geschlechtsapparate gehörigen Organe, sowie jene Gebilde, welche man subcuticulare Zellen nennt, intensiv und scharf gruin gefärbt, ferner treten noch eine Anzahl kleiner gritner Inselchen aus dem ungefärbten Gallertgewebe der sogenannten Mittelschicht hervor. Betrachtet man letztere mit scharfen Systemen, so findet man, wie schon oben besprochen, einen deutlichen Kern von einer spärlichen, fein gekörnten Plasmamasse umgeben (Fig. $1 \mathrm{k}$ ). Untersucht man die subcuticulare Schicht genauer, so zeigt dieselbe ein eigenthümliches Aussehen. Bestimmte Form repräsentirende Zellen, wie zum Beispiel pallisaden- oder spindelförmige Zellkörper, sind nirgends zu sehen. Dagegen breitet sich eine gänzlich unbestimmbare, .bizarre Gestalt besitzende Protoplasmamasse oder vielleicht besser gesagt Zellzubstanz ${ }^{1}$ ) auf den zwischen den Lakunen liegenden Gallertbalken nach allen Richtungen hin ans (Fig. 1, 2pm).

Weit davon entfernt sich dem engen Rahmen einer histolo-

1) Bekanntlich wird unter dem Namen Protoplasma alles Mögliche zusammengewürfelt, was man anderweitig nicht hinzuthun weiss. Ueber das Wort Protoplasma und die Terminologie für die Zellstructuren findet man viel Interessantes in F le m m ing, Zellsubstanz, Kern und Zelltheilung. Mit 24 Textbildern und 8 Tafeln. Leipzig. F. C. W. Vogel 1882. p. 77-85. 
gischen Zelleintheilung anzupassen besitzt die ganze Masse eine gewisse Aehnlichkeit mit einem Plasmodium. Die Substanz brauchte sich nur zu bewegen und wir hätten im Kleinen ein täuschendes Bild eines jener wunderbaren Gebilde, welche meist im Innern faulender Pflanzen ihr Dasein fristen und eine netzförmig verzweigte, oder mit dünnen vereinzelten Strängen versehene weichfliussige zahlreiche Körner enthaltende, schleimähnliche Masse aufweisen.

Ich belege diese in der sogenannten Rindenschicht sich ausbreitenden Massen, da ich keinen passenderen Ausdruck finde, mit dem Namen: Protoplasmamantel, wodurch zugleich ansgedrückt werden soll, dass diese Massen mit ihren Verzweigungen die Lakunen mehr oder weniger umhilllen. Dieser Protoplasmamantel erstreckt sich mit seinen Ausläufern von der Cuticula bis an die, in der sogenannten Rindenschicht gelegenen, Dotterstöcke. Bei genauer Untersuchung aber scheint es, als existire zwischen diesen subcuticularen Massen und den erwähnten Protoplasmainselchen der sogenannten Mittelschicht ein gewisser Zusammenhang. Die in der letzteren nur spärlich und kleiner vorhandenen Kerne werden ganz allmählich nach der Cuticula zu häufiger und grösser, der den Kern umgebende Protoplasmahaufen wird ebenfalls ganz allmählich ansehnlicher.

Dicht unter der Cuticnla lässt sich der Protoplasmamantel am besten studiren. Immersionssysteme (Hartnack, homogene Immersion Nr. $2(\mathrm{z}=1 / 20 \mathrm{Z}$ oll, Vergrösserung 1010$)$ ausgezogener Tubus Ocular 3 Gasbeleuchtung, Abbé'scher Condensor) ergeben, dass seine Structur eine feinkörnige ist. In der körnigen Masse sind grössere und kleinere, mit dentlichen Kernkörperchen versehene, mit Jodgrün oder Hämatoxylin distinet hervortretende Kerne eingebettet (Fig. 1. 2. pmk). Auch Kalkkörperchen tinden sich darin (Fig. $2 \mathrm{kk}$ ). Jodgriun und Osmiumsäure heben die plasmatische Masse von der gallertigen Grundsubstanz deutlich ab und namentlich die Kerne werden durch die Osmiumsäure scharf contourirt und prall ausgerundet. Es braucht kaum erwähnt zu werden, dass von einer Zellmembran hier nirgends geredet werden kann. Gegen Reagentien: Alkalien, Essigsäure, Mineralsäuren verbält sich der Protoplasmamantel im Allgemeinen wie das Gallertgewebe, doch scheint er weniger resistent. Ausläufer dieser Plasmamassen sind, wie schon erwähnt, in den Porenkanälen von mir nicht gefunden 
worden. Ste udener ${ }^{1}$ ) lässt zwischen seinen pallisadenartig gestellten Subcutieularzellen in unregelmässigen Zwisebenräumen „bläschenartige oder becherförmige Gebilde" sowohl anf Quer- als auch auf Flächenschnitten auftreten. Er versichert, dass dies keine Kunstproducte sind. Nein, aber es sind die Lakunen im Gallertgewebe, welche aucb mir bei ungefähr 400 facher Vergrösserung grade so erschienen, wie Ste ud ener abbildet. Der Irrthum Steudener's, diese Hoblräume für besondere SchleimabsonderungsOrgane gehalten zu haben, ist wohl hauptsächlich den nicht ausreichenden Vergrösserungen zuzuschreiben, mit welchen er an diesem Kapitel gearbeitet hat.

Wenu ich jetzt an die sehr kitzligen Fragen: Welche Bewandtniss hat es mit diesem Protoplasmamantel? Zu welchen Functionen könnte er in Beziehung stehen? herantrete, so verheble ich mir keinen Augenblick, dass daruber etwas Positives auszusagen einstweilen unmöglich ist. Meine Untersuchungen über diese Fragen werde ich fortsetzen und mir vorbehalten, dariber später Naiheres zu berichten. Es ist meines Erachtens nicht möglich, befriedigende Aufschlisse iiber derartige Untersuchungen an todten und lange conservirten Thieren zu erlangen. Da man Solenophorus nur schwierig in dem erforderlichen Zustande erhalten kann, so muss anderes Material benutzt werden.

Wenn wir annebmen wollten, dass die subcuticularen Plasmamassen zur Ernährung in näherer Beziehung stehen, so ist folgender Weg der Ernährung möglich.

Nach den erwähnten Angaben vieler Autoren treten plasmatische Fortsätze der "subcuticularen Zellen" dureh die Porenkanäle.

Wenn von Roboz und ich ein solches Verhalten auch absolut nicht haben constatiren können, so liegt dies vielleicht daran, dass das Material durch zu lange Conservirung für diese Untersuchungen gänzlich unbrauchbar geworden war; die Möglichkeit eines solchen Verhaltens ist also nicht ausgeschlossen. Von Thanh offer ${ }^{2}$ ) will gesehen baben, dass vorgestreckte Protoplasmafüdchen der Epithelzellen der Diinndarmzotten Nahrungstheilchen aufnehmen; es ist also auch denkbar, dass durch die Cuticula tretende Plasmafort-

1) Ste udener l. c. p. 285. TA. XXVIII Fig. 1 u. 3 bz. u. Fig. 2 bz.

2) v. Th a n h of fer, Beiträge zur Fettresorption und histologischen Structur der Dünndarmzotten in Pflüger's Archiv Bd. VIII. 
sätze bei den Cestoden in ähnlicher Weise fungiren, und dass dann die fliissigen Nahrungsstoffe dureh das ganze Körperparenchym und dessen Liicken transsudiren.

Nach den schönen Untersuchungen Schiefferdecker's $\left.{ }^{1}\right)$ aber dringen bei Taenien die ernährenden Snbstanzen durch die Porenkanäle an den plasmatischen Fortsätzen vorbei, und seine weiteren Resultate ergeben, „dass sie sich dann in immer wachsender Grösse an allen freien Plätzen ansammeln und so die Matrixzellen mantelartig umgeben", „dass sie dann weiterhin durch den ganzen Körper des Bandwurms liberall, wo Platz ist, sich ausbreiten und so, ebenso wie die Matrixzellen, alle übrigen Gebilde, Bindegewebszellen, Muskelfasern und Nerven direct umbüllen. Alle diese Gewebselemente werden also ihr Ernährungsmaterial direct beziehen können, ohne ein Blut- und Lymphgefässsystem nöthig zu haben". Der negative Befund, den die Untersuchungen von von Roboz und mir hinsichtlich der plasmatischen Fortsätze ergeben baben, macht es erklärlich, dass, obgleich die Sache wie gesagt noch problematiseh, ich für Solenophorus eher zur S chi eff e rdecker'schen Ansicht neige, als zu der von Thanh offer's. Dann sind die "freien Plätze" Schiefferdecker's nichts anderes als die Lakunen des Gallertgewebes, und diese stehen durch die Porenkanäle direct mit der Aussenwelt in Verbindung ${ }^{2}$ ). Der Protoplasmamantel wird alsdann nur indirect oder gar nicht der Ernährungsfunction dienen. In den Lakunen finden wir dann ein hämolymphatisches Gefüsssystem, welches, wie bei den Mollusken, nach aussen offen steht. Auf solche Verhältnisse, welche ich für die wahrscheinlichsten halte, werde ich nachher zurückkommen.

Endlich könnte es möglich. sein, dass der Protoplasmamantel mit den Reproductionsorganen der Cestoden zusammenhängt. Ich erinnere an die eigenthümlichen Verhältnisse, welche bei der Bildung der Ovariolen der luftathmenden Arthropoden vorkommen,

1) Schiefferdecker l. c. p. $480-484$.

2) Leydig (die Hautdecke und Schale der Gastropoden etc. Arch. f. Natg. 1876. p. 213), Müller's Archiv 1855. Lehrbuch der Histologie p. 442) beschreibt bei Cyclus Cornea, Limax, Helix etc., dass die Epithellage des Fusses von Porenkanälen durchsetzt sei, mittelst derer die Bluträume mit der Aussenwelt in Verbindung stehen. Auch bei Anneliden (Ueber Phreoryctes Menkeanus, dieses Archiv Bd. I. p. 282) sind derartige Verhältnisse von dem genannten Forscher nachgewiesen worden. 
wie daselbst aus einer protoplasmatischen Masse mit eingestreuten Kernen, in der man jedoch die Grenzen der Zellen, welchen diese angehören, nicht erkennen kann, durch Vergrösserung einzelner Kerne und Bildung eines Protoplasmaballen um dieselben, das Urei entsteht.

Welche räthselhafte Function aber auch immer das besprochene Gebilde haben mag, epithelialer oder bindegewebiger Natur ist es sicher nicht. Eher haben wir es in dem in Rede stehenden Gebilde mit lebendiger Substanz zu thun, eher fungirt dasselbe wie der lebendige Protoplasmaleib einer Amöbe oder Foraminifere. Obne dass ein directer Nerveneinfluss erforderlich, ist es denkbar, dass der Protoplasmamantel seine Pseudopodien durch die Porenkanäle der Cuticula streckt, sei es um als Sinnesorgan sich über die Aussenverhältnisse zu orientiren, sei es um direct ernährende Verrichtungen auszutiben ${ }^{\mathfrak{1}}$ ).

Pintne $r^{2}$ ) kommt in seiner Beschreibung tiber den Bau des Kopfes von Tetrachynchus longicollis auf ahnliche Gebilde zu sprechen. Sie bilden eine Zellenlage zwischen Epithel und dem eigentlichen Parenchym. Er sieht diese Gebilde ungefähr so, wie ich den Protoplasmamantel beschrieben hahe, wäbrend aber dieser bei bei Solenophorus bis dicht unter die Cuticula reicht, lässt $\mathrm{Pintner}$ noch ein gesondertes Epithel bestehen. Er bringt diese Gebilde in Zusammenhang mit der Ernährung (p. 59).

Ich betrachte jetzt:

\section{Das Wassergefässsystem.}

Unter dem Ausdruck: Wassergefässsystem versteht man bei den Cestoden Röhren, die vom Scolex aus die ganze Strobila durch-

1) Vergl. zu diesen kurzen Bemerkungen über die Funktionen des Protoplasmamantels Th. W. Engel ma n n, Physiologie des Protoplasmas in Handbuch der Physiologie von S. Hermann, Bd. I. 1879; ferner die Arbeiten von R. Hertwig in Jenaische Zeitschrift Bd. XI. 1877. Fol in Mém. de la Soc. de Phys. etc. de Genève T. XXVI. 1879. G. Klebs, Form und Wesen des pflanzlichen Protoplasmas. Biolog. Centralbl. I. Nr. 16, 17, 19. Fl em ming, Zellsubstanz, Kern und Zelltheilung. Leipzig, Vogel 1882. K o $11 \mathrm{~m}$ a $\mathrm{n} \mathrm{n}$, Ueber thierisches Protoplasma, Biolog. Centralbl. II. 1882. Nr. 3 und 4.

2) Th. Pintner, Untersuchungen über den Bau des Bandwurm- 
ziehen. Nach Häckel ${ }^{1}$ ) soll man dieselben phylogenetisch als mächtig entwickelte schlauchförmige Hautdrüsen betrachten, ähnlich den Schweissdriisen der Säugethiere und gleich diesen aus dem Hautsinneshlatte entstanden.

Mit dem Eintritte der Metamerenbildung an der Scolexform wird nach C. Gegenbaur ${ }^{2}$ ) der terminale Abschnitt dieses Gefässapparates der ältesten Proglottide zugetheilt, in welcher er mit einer blasigen Anschwellung nnd einem Porns excretorius münden soll, die jüngeren Proglottiden erhalten nur Theilstiicke der Kanäle. Ueber das Verhalten des ganzen Kanalsystems bestehen bis heute sehr divergente Ansichten. Hinsichtlich der älteren Ansichten tiber dieses Gefässsystem verweise ich auf die ausserordentlich eingehende und ibbersichtliche Literaturangabe bei Ka hane, und berticksichtige selbst eingehender erst die Arbeiten des Ietzten Decenniums.

Was Sommer und Land ois ${ }^{3}$ ) eigentlich mit ihrem "plasmatischen Kanalsystem " bei Bothriocephalus gemeint haben, weiss Niemand, es hat auch Niemand dasselbe wieder beobachtet und es bleibt nichts anderes übrig, als dasselbe einstweilen ins Reich der Fabel zu verlegen ${ }^{4}$ ). Der Bericht, den die genannten Forscher iiber die eigenthümlichen Seitengefässe der Strobila - Anfang und Endigung wurden nicht untersucht - geben, ist kurz folgender: Es existiren jederseits zwei Seitengefässe, sie liegen in der sogenannten Mittelschicht, die zu innerst gelegenen beschreiben in den einzelnen Gliedern Bogen, die äusseren verlaufen grade und gestreckt. Der Durchmesser der inneren Seitengefässe ist stärker als der der äussekörpers etc. in Arbeiten aus dem zoologischen Institute Wien. 'T. III. 1881 p. $57 \mathrm{ff}$.

1) Häckel, Anthropogenie. Leipzig, Engelmann. 1874. p. 666 .

2) Gegen baur: Grundriss der vergl. Anatomie. 2. Auflage. Leipzig 1860. p. 185.

3) Sommer und Landois l. c. p. 47 a. T. VII Fig. 1.

4) Pintner (l. c. p. 58) allerdings sagt: „Das ganze Aussehen dicser hier besprochenen Gewebsschicht (es ist die von ihm p. 57 beschriebene zwischen Epithel und dem eigentlichen Körperparenchym gelegene Zellenlage höchst eigenthümlichen Characters gemeint) exinnert gewiss lebhaft an das von Sommer in seiner ersten Arbeit beschriebene, feine und äusserst zartwandige plasmatische Kanalsystem, mit einer Tränkungsflüssigkeit von mattem Fettglanz, und ich glaube nicht irre zu gehen, wenn ich seinen Fund mit dem beschriebenen Organsysteme identificire. 
ren, die Contouren der ersteren treten schärfer hervor als die der letzteren. Irgendwelche Commissuren unter den Gefässen gelangten nicht zur Beobachtung. Die äusseren Gefässe sind häufiger mit einer f'ein punktirten Masse gefüllt als die inneren. In den geschlechtsreifen Proglottiden gibt es jederseits als Fortsetzung des äusseren Gefässes der jungen Glieder nur einen Seitenkanal. Dic Seitengefässe werden von einem Balkenwerk eingerahmt, welches aus der bindegewebigen Grundsubstanz des Körperparenchyms hervorgeht.

Schneider-1) theilt einige Beobachtungen uber das Wassergefässsystem von M. Ehrenbergii mit. Daraus ist hier nur von Interesse, dass er allen Plathelminthen im Inneren besagter Gefässe stellenweise Wimperbesatz zuspricht, welchen er nach dem Beispiele von von Siebold aus Czermack'schen undulirenden Membranen bestehen lässt.

Nach Sommer ${ }^{2}$ ) gibt es an den unteren Gliedrändern von Taenia solium und medioc. zwischen den Wassergefässlängsstämmen Queranastomosen - wie schon Leuekart ${ }^{3}$ ), der auch Gefïssana. stomosen (Ringanastomose) im Köptchen von Cysticercus pisiormis abbildet"), nachwies - und wo diese in die Hauptstämme einmiinden, findet sich ein Klappenapparat, der aus zwei einander gegenüber liegenden Falten oder Duplicaturen der structurlosen Grenzhaut gebildet wird und der Flïssigkeitssäule nur einen Durchtluss gegen das Ende der Kette hin gestattet. Wimperhaare oder Wimperläppchen gibt es nicht. Die Kanalwände besitzen keine Contractilität. Der Inhalt der Gefässe gerinnt in Alcohol abs. und enthält Substanzen, die dem Xanthin oder dem Guanin sehr nabe stehen. Auch in dieser Arbeit ist die Rede von besonderen plasmatischen Längsgefässen, welche „Blnt" führen.

Nach Blumberg ${ }^{5}$ ) gibt es bei einigen Taenien in der Strobila

1) Schneider l. c. p. 93.

2) Sommer, Ueber den Bau etc. von Taenia medioc. und solium. Zeitschr. f. w. Zoologie. 1874. Bd. 24. H. 4 p. 515 u. 516. Anmerk. - Daselbst zu vergl. T. XLIII u. XLIV. Fig. $1 \mathrm{E}^{2}$.

3) Leuckart l. c. p. 171.

4) id. Blasenbdw. Fig. 9 T. IV.

5) Blumberg, Ein Beitrag zur Anatomie der T. plicata, perfoliata, mamillana. Arch. f. wissenschaftl. und prakt. Thierheilkunde. 1877. Bd. III. p. $39,40$. 
jederseits nur einen Längsstamm. Die Längsstämme entspringen im Scolex aus verıweigten Gefässen, welche mit den Porenkanälen der Cuticula in Verbindung stehen uud senden in den einzelnen Gliedern Aeste ab. Dem ganzen Kanalsystem kommt nach ihm die Function eines Darmes und Blutgefässsystemes zugleich $z u$, die Sangnäpfe repräsentiren den Mund. Aehnliche Ansichten finden sich bekanntlich schon in der älteren Literatur, so z. B. bei Nitz s ch und Owen, Brenner, Mehlis, Platner, Blanchard ${ }^{1}$ ).

Nach Steudener's ${ }^{2}$ ) schönen und eingehenden Untersuchungen besteht zwischen Taenien und anderen Cestodenfamilien hinsichtlich der Wassergefässe ein „durchgreifender Unterschied".

Bei ersteren beginnen dieselben im Scolex mit einem Gefässringe, der bei den verschiedenen Arten verschieden gestaltet ist, von diesem Ringe aus treten dann, oftmals vorher noch Schlingen und Knäuel bildend, die Seitengefässe in die Gliederkette ein. Deren gibt es in derselben jederseits zwei, anfangs gleich weit, später im Durchmesser verschieden. Das mit kleinerem Durchmesser versehene Gefäss hört endlich auf, ob es blind endigt oder in das grosse Gefäss einmündet blieb unermittelt. Am hinteren Rande jedes Gliedes aller Taenien gibt es eine Quer- nicht Ringanastomose zwischen den beiden mit grösserem Durchmesser versehenen Seitenstämmen. Die Ausmïndung des Gefässsystems geschieht bei Taenien im letzten Gliede mit einer Oeffnung der Queranastomose. $\mathrm{Ob}$ irgendwo ein Klappenapparat vorhanden, bleibt ungewiss.

Ganz anders sind die Verbältnisse bei Bothriocephalus. Im Kopfe mit feinen Gefässstämmen beginnend, verlaufen eine grosse Anzahl von Längsstämmen (bis 18) in der Strobila mit zahlreichen Anastomosen und münden alle im letzten Gliede gesondert aus. Eine contractile Blase existirt nirgends. Wimpervorrichtungen in den Gefässen kommen bei Cestoden nicht vor. Die Wandung der Wassergefässe ist überall eine structurlose Membran ohne jeglichen Muskelbelag. Der Inhalt der Gefässe ist bei allen Cestoden eine helle, wohl von Eiweiss freie Flüssigkeit.

Nach Zograf ${ }^{3}$ ) gibt es bei Triaenoph. nodul. jederseits nur ein einzelnes Gefäss, Wimpervorrichtungen konnte er nicht bestäti-

1) Vergl. die Literaturangabe bei Blumberg und bei Kahane.

2) Steudener 1. c. p. 287-292.

3) Zograf 1. c. p. 7. sq. 
gen. Nach Kahane ${ }^{1}$ ) durehziehen jederseits 2 Längsgefässe spiralig verlaufend die Strohila. Sie entspringen aus einem plexusartigen Gefässringe im Scolex und stehen mit einem den ganzen Körper durehziehenden feinen Capillarnetze in Verbindung. Zwischen ihnen treten Ringanastomosen anf.

Was die histiologischen Verhältnisse des Gefässsystems anbelangt, so lässt Kahane die Frage nach Wimpervorrichtungen offen Die Wandung ist eine structurlose Membran ohne eigenen Zellenbelag und ohne selbständige Contractilität. Klappenapparate in den Hauptgefässen wurden nicht aufgefunden.

Hinsichtlich der physiologischen Bedeutung des Apparates bemerkt Kahane, dass ,um als excretorisches Organ in der wahren Bedeutung des Wortes zu gelten, die Gefässe ein Epithel besitzen müssten". Da dieses nicht vorhanden betrachtet er dieselben als ein System von Ausführungsgängen, zu dem das Körperparenchym als eigentliche Drüse sich verhält. Nach Laczkó ${ }^{2}$ ) besteht das Wassergefissssystem von Tetrarbynchen aus Raja clavata aus 2 seitlich gelegenen spiralig verlaufenden Kanälen, die einer selbständigen Wandung entbehren und in der letzten Proglottide zu einer Ampulle zusammenfliessen.

Die letzten Jahre haben eine Reihe hochinteressanter Arbeiten und Ansichten ïber die Wassergefässe gebracht. Dahin gehören namentlich die schönen Untersuchungen Pintner's ${ }^{3}$ ) an Tetrabothrien und Tetrarhynchen.

Von besonderer Wichtigkeit sind namentlich seine Angaben über Flimmerbewegung im Bereiche des Gefässsystems, welche bekanntlich Böttcher ${ }^{4}$, Stieda $a^{5}$, Sommer und Land o is Steudener, Donnadie $\left.{ }^{b}\right)$, BIumberg, Zograf und Kabane vor ihm nicht aufzufinden vermochten. Im Zusammenhange mit den 4-20 Langskanälen existiren blindendigende Flimmertrichter,

1) Kahane 1. c. p. 203-208.

2) Laczkó, Zoolog. Anz. 1880. p. 429.

3) Pintner, Untersuchungen über den Bau des Bandwurmkörpers in Arbeiten aus dem zoolog. Institute der Universitat Wien und der zoolog. Station in Triest. T. III. Wien 1881.

4) Böttch er, in Virchow's Arch. Bd. 47. 1869. p. 370-372.

5) Stieda, Ein Beitrag zur Anatomie d. Bothriocephalus latus. Arch. f. Anat. u. Physiol. u. wissenschaftl. Medicin. 1864.

6) Donnadieu, Journ. de l'anatomie et de la physiologie etc. Paris 1877. 
welche einzellige ausscheidende Driisen reprïsentiren und den Anfang des ganzen Wassergefässystems bilden. Die Trichterzellen liegen in der Zone zwischen Körperparenchym und Epithel. Die glashellen Wandungen der Gefässe besitzen als Matrix ein besonderes Aussenepithel. „Der Grundtypus für den Verlauf der Längsgefässe ist eine einfache, bis an die Stirnwand des Kopfes vorgeschobene, aus einem dorsalen und einem ventralen Aste gebildete Schlinge in jeder Körperbälfte, deren Neigung zur Insel- und Anastomosenbildung bei den verschiedenen Arten eine Reibe complicirter Verlaufsformen liefert." Die Längskanäle communiciren durch eine Endblase oder mit besonderen Endöffnungen (bei Triaenophorus auch am Kopfe und Halstheile) mit der Aussenwelt: Alle Aeste, welche von den Längskanälen abgehen, ,kehren entweder zu den eigenen Muttergefässen zurïck, oder münden in benachbarte, so dass es nirgends blindsackartige Enden, beutelförmige Verästelungen oder ähnliche Bildnngen gibt; Communicationen mit Hohlräumen des Körpergewebes kommen nirgends vor." Die Angaben Pintner's sind also von denen friherer Autoren sehr verschieden.

Specielle Untersuchungen über den excretorischen Apparat bei Solenophorus liegen von Poirier ${ }^{1}$ ), Moniez ${ }^{2}$ und von Roboz ${ }^{3}$ ) vor. Poirier hat an Exemplaren, die nur kurze Zeit in Spiritus gelegen hatten, Injectionen angestellt. Es gibt sechs Längsgefässe, davon communiciren die innersten am Anfange jedes Gliedes durch Anastomosen. Die anderen Gefässe zeigen in den Gliedern keine Communication, bilden aber ,dans le scolex un réseau qui les réunit les uns anx autres." „Le vaissean externe, arrivé dans le scolex, s'enfonce plus profondément en passant sous les deux autres, monte le long de la fente, qui sépare les deux bothridies, jusque vers l'extrémité du scolex; là, il se divise en deux branches qui vont se ramifier dans chaque bothridie. Le vaisseau médian d'un calibre plus petit que celui des deux autres, passe au-dessus du vaisseau externe et, vers la moitié de la longueur du scolex, se bifurque

1) Poirier, Sur l'appareil excréteur du Solenophorus megalocephalus in Compt. rend. 1878. p. 1043-1045.

2) Moniez, Sur quelques points d'organisation du Solenophorus megalocephalus in Bulletin scientifique du Dep. du Nord. 2. Série p. 113-123.

3) v. Roboz l. c p. 271-276. 
en deux branches qui vont se réunir au résan formé par les branches de division du vaisseau externe.

Quant à vaisseau interne, il se bifurque immédiatement après son entrée dans la tête et forme un réseau à mailles très larges qui se réunit an réseau à mailles plus serrées provenant du vaisseau externe. Les trois paires de vaisseaux ne forment dont q'uun seul système.

Aussel diesem Gefässsystem soll es noch ein oberflächliches als Circulationsapparat geben, der mit dem ïbrigen Gefässsystem communicirt und zwar durch Verzweigungen eines in jedem Gliede sich findenden Astes des äusseren Längskanales des tiefer gelegenen Gefässsystems.

Der Irrthum Poirier's binsichtlich der sechs Längsstämme wurde dann von Moniez, von dessen Arbeit ich selbst leider nicht Einsehen nehmen konnte, welcher die sechs auf vier reducirt, berichtigt. Des Letzteren Angaben schliesst sich von Roboz an. Hinsichtlich der Gefüssver\%weigung im Seolex stimmen seine Angaben im Allgemeinen mit denen von Poirier überein. Ein oberflächliches Wassergefässsystem im Sinne von Knoch') und Böttche $r^{2}$ ) findet von Roboz auch. Knoch. beschreibt es als zahlreich anastonosirendes Röhrensystem, das unmittelbar unter der Haut des Thieres liegt und Flimmer- und Körnchenbewegung zeigt. Böttcher, konnte dasselbe nur in Scolex und in den jüngeren Gliedern, nicht mehr in den reifen Proglottiden seben. Der Inhalt der betreffenden Kanäle ist wasserhell; Flimmerung zeigt sich nicht. Die Endigung der feinsten Wassergefässe im Sinne von Bütschli ${ }^{3}$, Fraipont ${ }^{4}$ ) und Pintner ${ }^{5}$ ) konnte von Roboz an seinem Material nicht zur Darstellung bringen. Weiter berichtigt von Roboz dann den Irrthum Laczkó's, dass die Wassergefässe membranlos seien, und weisst die Ansicht von Pintner zurick, dass sie einen äusserlichen Epithelbelag führten. Eine wesentlich

1) Knoch, Naturgeschichte des breiten Bandwurms. 1862. p. 118 u. 119.

2) Böttcher in Virchow's Arch. Bd. 47. 1869. p. 370-372.

3) Bütschli, Bemerkungen über den excretorischen Gefässapparat der Trematoden. Zool. Anzeiger. 1879. Nr. 41.

4) Fraipont, Recherches sur l'appareil excreteur des Trematodes et des Cestodes, in: Extrait des Archives de Biologie publiées par van Beneden. V. 1. 1880 . p. $415-456$.

5) Pintner l. c. 
neue Beobachtung, welche von Roboz gemacht haben will, ist, dass die im Scolex und in der Strobila verlaufenden Längskanäle und die Anastomosen zwischen den beiden inneren Längskanälen eigene aus Ring- und Läng'sfasern bestehende Muskulatur besitzen.

Meine Untersuchungen haben ergeben, dass es in der Strobila jederseits zwei Längsgefässe gibt (Fig. $8 \mathrm{ik}$. ek). Dieselben nehmen in dem Scolex ihren Ursprung and ziehen durch sämmtliche Glieder. Sie liegen ausschliesslich und allein in der von Eschricht und Leuckart als Mittelschicht bezeichneten Körperpartie innerhalb des starken Ringmuskelschlanches. Ob von Roboz ganze Querschnitte durch die Proglottide gelegt hat, weiss ich nicht, jedenfalls gibt er keine Abbildung eines derselben, auf welchem man die Lage der Wassergefässlumina erblicken könnte. Fast muss man bei seiner Darstellung manchmal zweifeln, dass er die Längsstämme überhaupt auf dem Querschnitte gesehen hat; denn er sagt bei der Gelegenheit der Besprechung von einem etwaigen Zusammenhange der Kalkkörperchen mit dem Gefässsystem, in der Mittelschicht sei keine Spur eines Wassergefässsystems vorhanden ${ }^{1}$ ). Dies wäre seinerseits ein starker Irrthum. An einer anderen Stelle (p. 273) heisst es dann, dass die Längsgefässe ,am Rande der Mittelschicht" verlaufen. Aus solchen sich widersprechenden Aeusserungen ist es schwer sich über die eigentlichen Ansichten des Autors zu orientiren.

Von den beiden Längsstämmen hat der zu innerst gelegene das weiteste Lumen (Fig. 8e k). Auf gelungenen Querschnitten wenig geschrumpfter Glieder beträgt dasselbe $0,175 \mathrm{~mm}$, das des nach aussen gelegenen Gefässes dagegen nur $0,05 \mathrm{~mm}$. Je weiter sich die Glieder dem Ende nähern, desto stärker wird der innere Seitenstrang, während der äussere annähernd das gleiche Lumen bis zuletzt beibehält, nicht aber enger wird, wie von Roboz ${ }^{2}$ ) es meint. Dass in den bereits geschlechtsreifen Gliedern die Verbreiterung des inneren Längsstammes plötzlich inne hält, um einer Abnahme des Gefässdurchmessers wieder nachzugeben, ein Umstand, auf welchen Pintner ${ }^{3}$ ) bei Calliobothrium verticillatum und auf welchen schon frtiher J. P. van Beneden ${ }^{4}$ ) aufmerksam machte,

1) v. Roboz 1. c. p. 270 Zeile 14 und 15.

2) v. Roboz p. 273

3) Pintner l. c. p. 29.

4) J. P. van Beneden 1. c. p. 257. 
kaun ich bei Solenophorus nicht bestätigen. Die inneren starken Seitengetässe verlaufen nicht in grader Linie, sondern beschreiben in den einzelnen Proglottiden einen wellenförmigen Weg. In den Anfangsgliedern sind die Wellen der geringeren Grösse der Proglottiden entsprechend kürzer als in den dem Ende näher gelegenen. Der Verlauf der engeren äusseren Seitengefüsse dagegen ist ein gerader, und so komml es denn, dass auf dem Querschnitte diese letzteren bald näher, bald entfernter von den Innengefässen lagern. Dass die genannte verhältnissmässig regelmässige Wellenlinie des inneren Längskanales durch Muskelcontraction hervorgerufen wird, scheint mir durchaus unwahrscheinlich, ich glaube vielmehr, dass wir anzunehmen berechtigt sind, in dieser Scblängelung eine grössere Flächenentfaltung erblicken zu dürfen.

Wenn ich, wie die meisten anderen Autoren von inneren und äusseren Längsgefässen rede, so geschieht dies deswegen, weil man auf geeigneten Querschnitten das Lumen des schwächeren Gefässes mebr dem Proglottidenrande zugeriickt findet.

Doch darf man sich nicht denken, dass die zwei in Stärke verschiedenen Seitenstämme auch gleichzeitig in dieselbe parallel zur Fläche des Gliedes durch dieses gelegte Ebene fallen, nein, die Verhältnisse gestalten sich vielmehr so, wie auch neuerdings Pintne ${ }^{1}$ ) besonders hervorhebt, dass das stärkere Gefäss am nächsten der ventralen Gliedfläche liegt, während das schwächere der dorsalen Fläche näher verläuft (vergl. Fig 8 u. 9). Was die Endigung der 4 Seitengefässe anbelangt, so habe ich jedes derselben stets mit einer besonderen Mündung nach Aussen am hinteren Proglottidrande angetroffen. Dass das schwächere Gefäss blind endige, oder in das stärkere einmünde, muss icb für Solenophorus bestreiten. Von dem Vorkommen einer Endblase kann ich nichts berichten, da an dem Untersuchungsmaterial, welches mir zur Disposition stand, das ursprïngliche Körperende nicht mehr vorhanden war. Eine schrittweise Bildung eines Porus excretorius, wie Le u ckar $\left.\mathrm{t}^{2}\right)$ für $\mathrm{T}$. cucumerina angibt, kann ich für Solenophorus nicht bestätigen. Besondere Ausmündungen der Hauptstämme am Kopfe oder Halse, wie Pintner ${ }^{3}$ ) bei Triaenophorus nodulosus be-

1) Pintner 1. c. p. 30 .

2) Leuckart 1. c. p. 172 .

3) Pintner 1. c. an verschiedenen Stellen. 
schreibt, finden sich bei Solenophoras nicht. Inselbildungen an den Längsstämmen der Strobila, konnte ich mit Ausnahme der dem Scolex am nächsten liegenden Halspartie nicht wahrnehmen.

In der Nähe des hinteren Randes eines jeden Gliedes existirt zwischen den inneren Längsgefässen eine diesen an Stärke fast gleichkommende Queranastomose (Fig. 9 qa). Sie besteht aus einem schwach geschlängelten, nicht ringförmig gebildeten Communicationskanal, welcher eine oder mehrere Abzweigungen zeigt, von denen einige in die Hauptanastomose zurücklaufen (Fig. 9 i a), andere aber allmählig in die Lakunen des Gallertgewebes ubergehen (Fig. 11.1 a). Weitere Anastomosen zwischen den stärkeren Seitengefïssen, oder zwischen den schwächeren, oder zwischen den stärkeren und schwächeren finden sich nicht. Manchmal erreicht der von dem Hauptgefäss abgehende Ast dasjenige der anderen Seite nicht, es kommt dann nicht zur vollständigen Anastomose, sondern der Ast geht ebenfalls in das Lakunensystem tiber (Fig. 11 la). Auf diese Thatsachen, dass die centralen Theile des Gefässsystems mit den Lakunen communiciren, lege ich Gewicbt! Wie steht es nun mit der Gefässvertheilung im Scolex? Die Schilderung, welche $v$ on Roboz ${ }^{1}$ ) tiber dieselbe gibt, ist nicht darnach angethan, die Verbältnisse klar zu legen. Auf die wundervollen und klaren Darstellungen Pintner's, deren genaues Studium jedem Beobachter bei Untersuchungen ỉber das Wassergefässsystem des Scolex willkommen sein muss, geht von Roboz gar nicht näher ein.

Nach meinen Untersuchungen muss ich die vier Wassergefäss. längsstämme mit Pintner einfach als Theile zweier Gefässschlingen betrachten, welche um die Bothridien des Scolex sich herumlegen. Um jede der Haftscheiben läuft in gleicher Dicke eine Gefässschlinge, und die beiden Enden derselben treten in gleicher Dicke in den Halstheil ein (Fig. 12), um als Längskanäle in der oben beschriebenen Weise durch die ganze Strobila zu verlaufen.

Die von Pintner beschriebene Inselbildung, kommt im Scolex von Solenophorus auch vielfach vor. Es zweigen sich nämlich von dem Muttergefäss über kürzere oder längere Strecken Gefüsspartien ab, um dann wieder in das Muttergefäss zurückzukehren. Diese Nebenarme besitzen dieselbe Stärke wie das Muttergefäss.

1) v. Roboz 1. c. p. $273-274$. 
Ein Scolex, in welchem unter der Lupe ein Theil des Gefässapparates mit Berliner Blau injicirt wurde, gibt nach oberflächlicher Entkalkung und gründlicher Aufhellung in Nelkenöl, ein Bild wie es Fig. 13 zeigt.

Das Präparat war durch die Manipulationen, die damit vorgenommen und die durch die lange Alkoholconservirung sehr erschwert wurden, stellenweise stark defect geworden, aus Mangel an Material konnte ich die Versuche nicht wiederholen. Man sieht drei gleich starke Gefässe $(\mathrm{g} f)$ in dem oberen Halstheile, das vierte ist nicht injicirt. Die Gefässe legen sich dann im Scolex in Form einer Schlinge um die Bothridien. An mehreren Stellen (i) kommt es zur Inselbildung, das Gefässstiick $\mathrm{g}$ scheint einem Nebenarme als weitere Verästelung anzugebören.

Die Inselbildung der Gefässschlingen lässt sich ebenfalls auf Längsschnitten verfolgen, welche man in die Ebene der Schlingen durch die Bothride legt. Auf einem Querschnitte durch den Hals (Fig. 12) findet man nur die vier mit gleichem Durchmesser ausgestatteten Lumina der beiderseitigen Gefässschlingen. Die Inselbildung hat noch nicht begonnen. Legt man aber den Querschnitt ungefähr durch die. Mitte des Scolex, so erhält man von den Hauptwassergefässen ein Bild, wie es Fig. 14 repräsentirt: Ringsum die Haftscheiben sehen wir durchschnittene Zweige der Gefässschlingen (Fig. $14 \mathrm{~g} \mathrm{f}$ ), bier sipd sie horizontal, quer, dort schräg, an anderen Stellen längs getroffen, je nach der Richtung, in welcher sie den Saugnapf umlaufen. Was der ursprïngliche Schlingenstamm, was die Abzweigungen sind, lässt sich, um so mehr, da alle Theile der Gefässschlinge gleiche Stärke besitzen, naturlich nicht erkennen.

Quer- oder Ringcommissuren zwischen den beiderseitigen Gefässschlingen im Scolex, in der Weise, wie es Pintner für einige Cestoden beschreibt, scheint es hei Solenophorus nicht zu geben, wenigstens gelang es mir nicht derartige Verbältnisse nachzuweisen. Die schematische Zusammenstellung, welche von Roboz vom Wassergefässsystem des Scolex in seiner Figur 6 gibt, entspricht dem thatsächlichen Verhalten desselben nicht.

Klappenvorrichtungen habe ich im Gefässapparate trotz sorgfältigen Nachsuchens nirgends finden können, glaube somit auch nicht, dass dieselben vorhanden sind.

Die Fage, ob die Gefässe stellenweise Wimperbesatz tragen, 
wie schon einige fribere Autoren: Me issne $\mathbf{r}^{1}$ ), Leuck art u. a.m. angeben, muss ich offen lassen, das lange Aufbewabren des Materials in Alkohol lässt eine Entscheidung über derartige Verhältnisse nicht zu. Was den histologischen Charakter des bis jetzt besprochenen Theiles des Gefässapparates anbelangt, so konnte ich durch meine Untersuchungen eine besondere Muskulatur in der Wand der Längsgefässe, wie sie durch von $R_{0 b o z}{ }^{2}$ ) beschrieben wird, nicht auffinden. Pintn e ${ }^{3}$ ) behauptet, „im Gegensatze zu allen bisherigen Darstellungen, dass die Hauptstämme des Wassergefässsystems ein wohlausgebildetes Epithel besitzen, das zweifelsohwe als Matrix ihrer glashellen homogenen Membran aufzufassen ist. von $\mathrm{Roboz}^{4}$ ) hat für Solenophorus ein solches Vorkommen zurickgewiesen. Mich haben diese Pintner'schen Angaben ausserordentlich interessirt und speciell für Solenophorus neugierig gemacht. Mit allen möglichen technisch histologischen Hülfsmitteln bin ich bestrebt gewesen, das Pintner'sche Epithel mir ad oculos zu demonstriren. Ich finde Folgendes: Die glashelle Wandung der Wassergefässe ist nicht das Product von Matrixzellen, sondern als structurlose Membran eine Ausscheidung des Gallertgewebes.

Aber es gibt in dem Gallertgewebe noch eine Art von Zellen, welche ich nur in dem Bereiche der Wassergefässlängsstaimme und deren Queranastomosen sehe. Sie finden sich in dem Gallertgewebe eingebettet, auf Quer- und Längsschnitten den Gefässen bart angelagert. Sie sind oval, messen mit ihrer lïngsten Axe $0,02 \mathrm{~mm}$, nit der kurzen Axe $0,015 \mathrm{~mm}$. Sie bestehen aus einem körnerreichen Protoplasma, in welchem ein central gelegener, im Durchmesser $0,005 \mathrm{~mm}$ grosser Nucleus sich befindet. Das Gallertgewebe hat nm den Protoplasmaleib eine structurlose Membran abgesondert. In dem Protoplasma liegen allerhand farblose Concremente (Fig. 3-6, $11,15 \mathrm{dz}$ ), welche dafür sprechen, dass wir diese Gebilde wahrscheinlich als einzellige Drisen anzusehen haben. Die Bedeutung der Drüsenzellen tritt uns in dem Körper mancher niedererThiere in frappantester Weise entgegen, indem wir bei denselben oftmals Gebilde finden, welche wie drisige Organe functioniren und dabei nur aus einer

1) Meissner, Zur Entwicklungsgeschichte und Anatomie der Bandwïrmer. Zeitschr. f. wissenschaftl. Zool. Bd. V. p. 388 sq.

2) v. Roboz l. c. p. 275.

3) Pintner l. c. p. 21.

4) v. Roboz l. c. p. 275 . 
einzigen Zelle besteben. Dass solche Drüsenzellen oft einen epithelialen Character repräsentiren, ist bekannt, ich brauche nur an die Drissenzellen anf den Falten des Bojanus'schen Organes zu erinnern; indessen zu ihrer physiologischen Leistung bedarf die Driisenzelle mehr Körperlichkeit als eine einfache epitheliale Platte sie besitzt. Ob die beschriebenen Zellen wie ich glaube mit der Bildung der hernach $\mathrm{zu}$ besprechenden Kalkconcremente in Zusammenhang stehen, werden weitere Untersuchungen, namentlich an frischen Objecten festzustellen haben.

Bis zu den schönen Untersuchungen Pintner's haben sich die Stadien über das Wassergefässsystem der Cestoden, speciell über die soeben besprochenen Verbältnisse erstreckt. Mehr oder weniger ausser Acht gelassen hatte man dagegen den feineren Bau der peripherischen Wasserkanälchen, welche sowohl mit den inneren als auch äusseren Längsstämmen im Zusammenhange sich tiberall im Körper verzweigen. Namentlich der Ursprung der feinsten Wassergefässverzweigungen ist es, iiber welchen wir Pintner's Untersuchungen viel Wichtiges und Werthvolles verdanken. Ausser ihm hat Kahane feine Verzweigungen gesehen und Schneider ist der einzigste der Forscher aus den siebziger Jahren, welcher dem Wassergefässsystem sehr feine Ausläufer zuschreibt, an welchen sich ein becherförmiger Anhang ohne erkennbare Oeffnung befindet.

Bei Solenophorus finde ich folgende Verhältnisse: Wie schon erwähnt, besteht die Körpersubstanz dieses Cestoden aus Gallertgewebe, in welchem sich uberall mehr oder wenige grosse Gewebsliicken vorfinden. In diesen bemerkt man, nach der Peripherie des Gliedes an Häufigkeit zunehmend, sowohl im Scolex als auch in den sämmtlichen Proglottiden eigenthümliche Gebilde, welche sich ohne Anwendung von starken Systemen namentlich an älterem, lange Zeit conservirtem Material wie Zellkerne ausnehmen.

Es ist durchaus nicht unwahrscheinlich, dass dieser Umstand diejenigen Beobachter, welche die Gewebslitcken nicht als solche erkannt, verleitet hat, die hellen Räumen, in denen besagte Gebilde vorkommen, für Zellen eines „grossblasigen Bindegewebes" zu nehmen. Wendet man aber gute Tinctionsmittel: Hämatoxylin, Jodgrün, gewisse Azofarbstoffe und starke Vergrösserungen an, so entpuppt sich der vermeintliche Zellkern als etwas ganz anderes, nämlich als der Endapparát der feinsten Verzweigungen der Wassergefässe. 
Dieselben sind zuerst von Schneide $\mathbf{r}^{1}$ ) als solche erkannt und er lässt sie mit becherförmigen Anbängen, welche eine lange Wimper tragen besetzt sein. Seine Angaben aber sind von den späteren genannten Forschern nicht bericksichtigt und verfolgt worden, bis endlich Pintner ${ }^{2}$ ) sein Augenmerk auf dieselben richtete und seine weiteren eingehenden Untersuchungen daran schloss. Ich kann die Pintner'schen Beobachtungen für Solenophor'us bestätigen. Die Wassergefïssendapparate sind auch hier trichterförnige Gebilde (Fig. 3. u. $11 \mathrm{t}$ ), welche unmessbar feinen, sich vielfach in- und durcheinander schlängelnden Capillargefässen aufsitzen. In dem Hohlraum des mit glasheller Wandung ausgestatteten Trichters liegt ein mehr oder weniger konischer, mit der Spitze der Trichterverengung $\mathbf{z u}$ gekehrter Körper (Fig. 5p). Ob dieser im Leben eine schwingende Membran, eine wimpernde Platte oder eine starke Geissel, lässt sich an den Prïparaten nicht mehr beurtheilen. Dass aber dieses Gebilde im lebenden Bandwurme bei der Wimperbewegung eine Rolle spielt, glaube ich mit Berücksichtigung der Pintner'schen Untersuchungen annehmen zu dürfen. Pintner lüsst die Trichter durch eine membranlose, mit plasmatischen Ausläufern versehene kernführende Zelle abgeschlossen werden.

Wenn es mir trotz eifriger Bemühungen auch nicht gelungen ist, diese so schön und klar zu Gesichte zu bekommen, wie Pi n tne r sie abbildet ${ }^{3}$ ), so habe ich durch die trümmerhaften Reste, die sich in den Präparaten davon erhalten haben, doch einigermassen die Ueberzeugung gewonnen, dass das von Pintner beschriebene Verhalten auch beim lebenden Solenophorus zutreffen möchte. Vor dem Trichtermund sehe ich oft einen Kern mit einem oder mehreren Kernkörperchen liegen (Fig. 3 u. 5 tk), nur einige Male sah ich deutlich, dass eine spärliche, unregelmässig geformte, wasserhelle plasmaartige Masse den Kern umgab (Fig. $5 \mathrm{kpt}$ ), in den bei weitem meisten Fällen finde ich nichts dem Trichter vorgelagert. Die Länge des Trichters beträgt $0,01134 \mathrm{~mm}$, seine grösste Weite $0,00378 \mathrm{~mm}$. Wie schon $\mathrm{Pintne} \mathrm{r}^{4}$ ) eruirt hat, sind diese Trichter wabrscheinlich die von Schiefferdecker beschriebenen Nervenendapparate.

Was nun die capillaren Ausführungsgänge des Trichter an-

1) Schneider 1. c. p. 93 .

2) Pintner l. c. p. 13 sq.

3) Pintner 1. c. T. II Fig. 3.

4) Pintner l. c. p. 15, 16. 
betrifft, so kann ich mit Pintner nur vor der Vorstellung warnen, dieselben wie z. B. Meis sner $r^{1}$ ) es thut, als die feinsten Verzweigungen des centralen Gefässsystems aufzufassen. Die Flüssigkeit, welche den Inhalt des Wassergefüsssytems bildet, bewegt sich centripetal. Die capillaren Gefässe sind Ausfiuhrungsgünge der Trichter und münden als solche in die centralen Theile des Apparates ein. Die Capillaren machen auf ihrem Verlaufe allerhand Biegungen und Schlingen, bilden stellenweise zahlreiche Anastomosen and oft fliessen mehrere in eine zusammen, wobei aber das Lumen an Stärke so gut wie nicht zunimmt, so dass also sämmtliche Capillaren, bis zu ihrer Einmiundung in die Seitenlängsstämme oder deren Anastomosen taberall gleich weit erscheinen.

Die Einmündung der Capillaren in die Längskanäle geschieht selten isolirt, sondern meistens vereinigen sich mebrere vor der Einmündung zu einem Delta (Fig. 3, 11, 15 $\triangle$ ). Aehnliche Apparate wie die Trichter hat Thiry ${ }^{2}$ ) bei Cercaria macrocerca und $\mathrm{B}$ ü tschli ${ }^{3}$ ) bei anderen Trematoden gefunden. Ich gehe jetzt un der Frage iiber : Wo liegen die trichterförmigen Anfänge des Wassergefüsssystems?

Ioh finde sie immer in den Lakunen, manchmal hart an der vom Gallertgewebe gebildeten Wand, manchmal mitten im Hohlraume. Die Capillaren verlaufen in den interlakunären Gallertstrüngen, wo sie sich vielfach treffen. Durch die Behandlung des Materiales bis zur Fertigstellung eines Priparates tritt hänfig ein Abbrechen der Trichter von ibren Capillaren ein. (Fig. 3 u. 5 a t). Oftmals sieht man in der Lakune ïberhaupt keinen Trichter melr, sonderu nur der Kern der ihm aufsitzenden Zelle ist zmriickgeblieben (Fig. $5 \mathrm{tk}_{1}$ ). Ein solches Bild macht anfangs den Eindruck, als hätte man wirklich eine kernhaltige Zelle vor sich.

Aber jeder Gedanke, dass diese „blasigen Hohlräume“ Zellen sind, muss schwinden, wenn man dieselben mit einander communiciren sieht und wenn man an gut erhaltenen Stellen die Trichter darin findet. Pintner hat die Lakunen als solcbe nicht erkannt und hebt besonders hervor, dass die Trichter nicht etwa mit Lakunen in Verbindung zu denken seien.

1) Meissner l. c.

2) T hiry, Beiträge zur Kenntniss der Cercaria macrocerca. Zeitschr. f. w. Zoolog. Bd. X.

3) B ü $\mathrm{sch} l \mathrm{i}$, Bemerkungen über den excretorischen Gefüssapparat der Trematoden. Zool. Anz. 1879. Nr. 42. p. 588 u. 589. 
Wie früher erwähnt bat schon Schneider ${ }^{1}$ ) die Lakunen gesehen, aber seine Angaben sind ron späteren Forschern wenig berücksichtigt worden.

Mit dem Eifer entwicklungsgeschichtliche Studien auf die verschiedensten Repräsentanten des Thierreiches zu übertragen seben wir auch das Interesse an Spalten, Lücken oder Hohlrüumen zunehmen, welche sich in den Geweben des Körpers vorfinden.

Ray-Lankaster ${ }^{2}$ ) gedenkt der Lakunen bei der Besprechung: des Vorkommens des Mesoblasts und des damit zusammenbängenden sanguino-lymphatischen Gefässsystems.

„In all Triploblastica" — so sagt er — „it (nämlich das blood-lymph-system) is represented by lacunae or channels, or by mere wide setting of the cellular elements of the mesoblast, between and around which the movement of a fluid, so-called lymph, is possible.

A blood-lymph-system or series of channels appears inits simplest form in the flat worms, where the main portion of those channellings in the mesoblast, sometimes spoken of as ,watervascular-system", must be regarded as the commencing differentiation of the bloodlymph-vascular-system". Und weiter: "The channels of the water vascular-system in those cases are seen in section to be intersected by long branching cells; they are, infact, only partial excarations of the mesoblastic tissue".

Ray-Lankaster erblickt in dem Wassergefässsystem (Lacunen und Kanäle) den Ausgangspunkt für die Bildung der Leibeshöble und der Blutgefässe und das System der Wassergefässe ist sowohl excretorischer als auch sanguino-lymphatischer Apparat, wo der eine aufhört und der andere beginnt bleibt unentschieden.

Fraiponts) hat ebenfalls Gewebslücken und Trichter der Wassergefässe gesehen, äussert aber seine Meinung, im Gegensatze zu Ray-Lankaster, reservirt dahin, dass der ganze Gefässapparat excretorischor Natur sei ${ }^{4}$ ).

1) Schneider l. c. p. 77 .

2) R a y-Lankaster, On the primitive Cell-layers of the Embryo. Annals et Magazine of natural History etc. Vol. XI. 4. Series. 1873. p. 331 u. 332 und später: Notes on the embryologie and cassification of the animal kingdom etc. Quarterly Journal of microsc. sc. Vol. XVII. 1877.

3) Fraipont, Recherches sur l'appareil l'excréteur des Trématodes et des Cestodes. Aŕchives de Biologie T. II. Fig. 1.

4) Ich war gezwungen F raip o n t's Meinung aus zweiter Hand kennen 
Aus einem Missverständniss der Lankaster'schen Ansichten seitens Fraipon t entsteht dann der ebenso hartnäckige als ergötzliche Federkrieg zwischen Ray-Lankaster und van Beneden') auf dem internationalem Gebiete des zoologischen Anzeigers.

Inzwischen erscheint noch die Arbeit der Gebrider Hertwig ${ }^{2}$ ), die in den Streit mit hineingezogen, denselben noch verwickelter macht.

Nach Villot existiren die Trichter der Wassergefüsse bei den Plathelminthen nicht ${ }^{3}$ ), die Existenz einer Leibeshöhle bleibt zu beweisen. Das Gefisssystem dient gleichzeitig der Absorption, der Respiration, der Circulation und der Excretion, wie Villot schon früher ${ }^{4}$ ) angegeben. Bei Hertwig's heisst es: „Von den Hauptstämmen gehen zahlreiche Seitenäste $a b$, die viel feiner wie jene sind, bis an ihr Ende ein gleiches Lumen trotz häufiger Verüstelungen beibehalten und untereinander durch netzförmige Anastomosen vereinigt sind." Eine ,seitliche Oeffnung" an den Enden der feinen Kanäle, mit einem undulirenden Wimperläppchen ausgestattet, tritt „mit den Gewebsspalten in Zusammenhang, welche nach allen Richtungen das Mesenchym durchsetzen."

Nach Hatsche ${ }^{5}$ ) mangelt den Platoden eine Leibeshöble und dadurch ist die characteristische Umbildung des Excretionsapparates, Mangel der Flimmertrichter und eine vielfache Verästelung der Excretionskanäle bedingt.

Die geradezu sich widersprechenden Ansichten über die Endigung der feinsten Wassergefässe und über Hoblräume im Körperparenchym der Plathelminthen seitens einer Reihe nenerer Beobachter

zu lernen, da es mir nicht möglich war, die Arbcit selbst zur Einsicht zu erlangen.

1) Vergl. Zool. Anzeiger Nr. 85, 91, 96, 101, 110.

2) 0 . und $\mathrm{R}$. H e r twig, Die Coelomtheorie: Versuch einer Erklärung des mittleren Keimblattes. Mit 3 Taf. Jena, Fischer 1881.

3) Villot, I'appareil vasculaire des Trematodes, considéré sur le doubles point de vue de sa structure et de ses fonctions in Zool. Anz. 1882. Nr. 121. p. 507.

4) id. Sur l'appareil vasculaire des Trématodes (C. R. de l'Académie des Sciences, Seance du 5. Juin 1876). Organis. et developpement de quelques. espèces de Trématodes endoparasites marins (Ann. des sc. nat. Zool. 6. Série. Tom VIII).

5) Hatschek, Studien über die Entwicklungsgeschichte der Anneliden in Arbeiten aus dem zoolog. Institut Wien. Bd. I. H. 3. 
haben mich mit besonderer Aufmerksamkeit diese streitigen Punkte verfolgen lassen. Dass die feinsten Gefässkanälchen mit Trichterorganen enden, steht nach Schneider's, Pintner's, und meinen Untersuchungen bei Solenophorus iiber allen Zweifel, dass diese Trichter in lakuniiren Hoblräumen liegen, muss ich ebenfalls als Thatsache hinstellen. Es bleibt jetzt noch zu erörtern übrig, was die Lakunen sind, und ob die Trichter mit dem Hoblraum derselben in irgend welcher Weise communiciren, oder gänzlich abgeschlossen sind.

Vor kurzer Zeit noch betrachtete man die Plathelminthen als parenchymatöse Thiere. Heute aber neigen eine Reihe von Forschern auf eingehende anatomische Untersuchungen, durch welche die Existenz von Hohlräumen in der Biudesubstanz ausser Zweifel gestellt wurde, gestiutzt, mehr dazu, diesen Würmern eine Leibeshöble zu vindiciren. Bei Landplanarien spricht Moseley ${ }^{1}$ ) von einer Leibeshöhle; bei der dureh $\mathrm{Thiry}^{2}$ ) genauer bekannt gewordenen Cercaria macrocerca giebt es ebenfalls eine solche. Auch $\mathrm{Graff}^{3}$ ) äussert in seinen Turbellarienstudien ähnliche Ansichten. Wenn man aber die Arbeiten der einzelnen Forscher miteinander vergleicht, und wenn man daraus die wichtigsten Resultate hinsichtlich des Vorkommens und der Beschaffenheit der sogenannten Leibeshöhle sich in ein tibersichtliches Resumé zusammenstellt, so fiihlt man dentlich, dass in der Bezeichnung Leibeshöhle wenig Uebereinstimmung, aber viele Willkür herrscht.

Es ist nun das grosse Verdienst der Gebrüder Hertwig, nachdem schon Huxley eine Nomenclatur gegeben, in die bisherige Unsicherheit des Begriffes Leibeshöhle einige Klarheit gebracht zu haben, indem sie je nach der abweichenden Entwicklung und Bildung der Leibeshöhle dieselbe als Enterocoel oder Pseudocoel hinstellen, wobei noch die Art und Weise des Verhaltens zur Bindesubstanz und zum Gefässsystem zu weiteren subclassificatorischen Benennungen fübrt.

Das von mir bei solenophorus nachgewiesene Lakunensystem

1) Moseley: On the anatomy and histology of the Laudplanarians of Ceylon: Philos. Transact. Vol. 164. Pt. I.

2) Thiry 1. c.

3) Graff, Kurze Berichte über fortgesetzte Turbellarien-Studien. Zeitschrift f. wissenschaftl. Zool. Bd. XXX. Suppl. 
repräsentirt nach meiner Ansicht geradeso die Leibeshöhle ${ }^{1}$ ), wie das der Mollusken, speziell der von mir nntersuchten Lamellibranchiaten $^{2}$ ). Ich belege sie mit dem ganz passenden, anch von Bitschli ${ }^{3}$ ) fïr Trematoden gebrauchten Ausdruck, ,rudimentïre Leibeshöhle", und zwar ans dem Grunde, weil ich mir über die Frage, ob die Leibeshöble der Cestoden und Lamellibranchiaten ein Enterocoel oder ein Pseudocoel (und zwar ein beginnendes Schizocoel) im Sinne der Gebrüder Hertwig ${ }^{4}$ ) bildet, bei dem Standpunkt der einschlägigen Entwicklungsgeschichte einstweilen kein Urtheil erlaube. Vorläufig neige ich hinsichtlich der Genese der Leibeshöhle noch am meisten zu der Hypothese der Engländer ${ }^{5}$ ), welche einem einheitlichen Ursprmng des Coeloms den Vorzug geben. In der Leibeshöhle liegen, wie schon erwähnt, bei Solenophorus die Trichter der Wassergefässe. Dieselben sind nach Pin $\iota n e r$ bei anderen Cestoden durch eine Zelle völlig geschlossen. Auch ich glaube, so weit es das conservirte Material zuliess, Reste solcher Zellen gesehen zu haben. Durch diese Zellen nun ist zwar eine directe, aber keine indirecte Communication des Gefässsystems

1) Griesbach, Das Gefässsystem und die Wasseraufnahme bei den Najaden und Myliliden. Zeitschr. f. w. Zool. Bd. 38.

2) Auch Kollmann (Ueber Verbindungen zwischen Coelom und Nephridium in Festschrift zur Feier des 500jährigen Bestehens der Julius-Maximilians-Universität Würzburg. Basel 1882.) hat neuerdings wieder für die Lamellibranchiaten eine Leibeshöhle beansprucht.

3) Bütschli l. c. p. 588 .

4) Nach Hertwig sind Plathelminthen und Mollusken Pseudocoelier. Vergl. I. c. p. 83 .

5) Balfour: Early stages in the development of vertebrates. Quart. journ. of micr. sc. Vol. XV. 1875. - id. A monograph of the development of elasmobranch fishes. London 18i8. - id. On the structure and homologies of the germinal layers of the Embryo. Quart. journ. of mier. sc. 1880. - id. Larval forms: their nature, origin and affinities ibid. 1880.

5) Huxley, On the classification on the animal kingdom. Quarterly journal of micr. sc. Vol. XV. 1875. - id. The anatomy of invertebrated animals. 1877. Uebers. von Spengel. Leipzig, Engelmann 1878. p. 561-765 u. $608-609$.

5) Ray-Lankaster I. c. - id. On the invaginate planula on diploblastic phase of Paludina vivipara. Quart. journ. of microsc. Vol. XV. 1875. - id. Notes on the embryology and classification of the animal kingdom: comprising a rivision of speculations relative to the origin and significance of the germ-lagers. Quart. journ. of micr. sc. Vol. XVII. 1877. 
mit der Leibeshöhle ausgeschlossen. Die Zellen sind, wie Pintner selbst hervorhebt, membranlos und fungiren wie eine einzellige Drise. Wenn nun eine solche Schlussvorrichtung der Trichter wirklich vorhanden ist, wie noch weitere Untersuchungen am lebenden Thiere festzustellen haben, dann dienen diese Zellen dazu, aus der in den Lakunen fliessenden concentrirten Ernährungsflïssigkeit nit Hülfe von Wimpervorrichtungen die Zersetzungsproducte in die Trichter und von da in die Kanäle zu führen, welche als Sammelröbren dieselben in die Hauptstränge zu leiten hätten. Dann hätten Ray - Lankaster und die Vertreter seiner Ansicht Recht, dass nämlich die Lakunen und die eigentlichen Wassergefässe zwei verschiedenen Systemen angehörten. Physiologisch verschieden: denn die Leibeshöhle repräsentirt wie bei den Mollusken vorzugsweise einen hämolymphatischen Gefässapparat; die peripherischen und

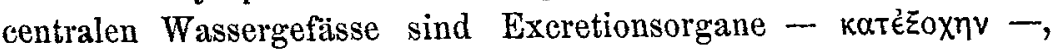
ob auch entwicklungsgeschichtlich verschieden, muss einstweilen eine offene Frage bleiben. Dann münden also die Excretionsorgane auch bei den Cestoden in die Leibeshöhle, ein Umstand, den von Ihering ${ }^{\text {) }}$ bei den Wuirmern für eine allgemeine Einrichtung hält.

Im Znsammenbange mit dem Wassergefässsystem betrachte ich jetzt

\section{III. die Kalkconcremente,}

welcbe ïherall im Körper des Cestoden verbreitet sind, nach der Peripherie aber an Zahl zunehmen.

Nach Virchow ${ }^{2}$ ) sind dieselben als verkalkte Bindegewebszellen aufzufassen. Nach Stied ${ }^{3}$ ) bleibt auf Zusatz von Essigsäure eine Contonr an Stelle des fruheren Körpers zuriack, in der Entstebungsweise schliesst er sich der Virchow'schen Ansicht an. Rindfleiseht) giebt zwar über ibre physiologische Bedeatung nichts, berührt aber ihr Verhältniss zur Bindesubstanz.

Er glaubt, „dass organische Gebilde, welche eben diese Form

1) von Ibering, Einiges Neue über Mollusken. Zool. Anz. 1879. Nr. 23. p. 138. Zeile 19, 20-26.

2) Virchow in seinem Arch. Bd. XI.

3) Stieda l. c. p. 180.

4) Rindfl eisch l. c. p. $141,142$. 
und Grösse haben, vom Centrum aus allmählich ganz und gar verkalken." Je nach dem verschiedenen Grade der Verkalkung und je nach der scbwächeren oder stärkeren concentrischen Streifung: unterscheidet er vier Species. Vielleicht hat man es in ihnen mit Amyloidsubstanz zu thun; aher bei der Jodpriifung nimmt das ganze Körperparencliym die jodrothe Farbe an, welche thierisches Amyloid kennzeichnet und grade die Kalkkörperchen bleiben ungefärbt.

"Zwischen den grossen kernhaltigen Zellen des Körperparenchyms - sagen Sommer und Land o is ${ }^{1}$ ) - finden sich in regellosen Abständen von einander die sogenannten Kalkkörperchen eingestreut (T. VII, Fig. 1 f.) ". Hinsichtlich der Natur treten die genannten Forscher der Ansicht Virchow's bei, dass dieselben als verkalkte Zellen der bindegewebigen Grundsubstanz aufzufassen seien.

Bei Bothriocephalen sollen die Concremente in der subeuticularen Schichte der "spindelförmigen Plasmazellen" fehlen. In der Grösse weichen die Kalkkörperchen nicht wesentlich von den grossen Zellen des bindegewebigen Körperparenchyms ab. Sie bestehen aus zwei Substanzen: dem „Stroma und dem kohlensauren Kalke". Ersteres lässt sich durch Lösen des Calciumrcarbonates in verdünnten Säuren isolirt darstellen. Auch der Kalk lässt sich isolirt darstellen, wenn man die Körperchen auf einer Glasplatte ausglitht, wobei das Stroma verbrennt und das Calciumcarbonat zurïckbleibt. Nur wenn grössere Mengen von Kalkkörperchen vorhanden sind, tritt auf Sïurezusatz ein Aufbrausen durch Freiwerden der Kohlensäure ein; geringe Mengen des Gases aber werden von "der Flüssigkeit des Präparates absorbirt" und zwar im „Entstehungsmoment" (in statu nascente). Eine Verbindung der Kalkconcremente mit dem Gefässsystem konnten Sommer und Lando is nicht constatiren, sie betrachten die Kalkgebilde auch nicht als ein Analogon einer Skeletbildung.

Schneider ${ }^{2}$ ) sagt, „dass die Kalkkörperchen aus der Verkalkung von Zellen oder Kernen hervorgehen, ist unbewiesen und durchaus unwahrscheinlich."

Nach Salensky ${ }^{3}$ ) liegen die Kalkkörperchen bei Amphilina

1) Sommer und Landois 1. c. p. 45.

2) Schneider l. c. p. 76.

3) Sa lensky l. c. p. 306-308. T. XXIX. Fig. 8 kk. 
foliacea in dem oberen Theile der Parenchymschicht. Manchmal trifft man zwei Kalkkörperchen verbunden, dann bat jedes einen centralen Kern. Sie enthalten nur wenige Kalksalze, brausen mit Säuren nicht und finden sich in den Bindegewebszellen selbst.

Schiefferdecker ${ }^{1}$ ) glaubt ebentalls, dass die Kalkkörper verkalkte Zellen seien und macht besondere Angaben, wie er sich die Verkalkung vorstellt.

Pintner ${ }^{2}$ ) findet, wie schon Pagensteche $r^{3}$ ) dass Kalkkörperchen oft in besonderem, von einer hellen Membran umgrenzten Höhlen liegen, dass sie aber mit dem Wassergefïsssystem in Zusammenhang zu bringen wären, scheint ihm unwahrscheinlich. Für Solenophorus findet von $\mathrm{Roboz}^{4}$ ) die Kalkkörperchen in der Rindenschicht an Zabl zunehmend - dem stimme ich vollständig bei. An ihren Zusammenhang mit dem Wassergefässsystem zweifelt er.

Diesen Angaben möchte ich für Solenophorus Folgendes hinzufügen:

Die Körperchen sind von verschiedenem Ausseben und von verschiedener Grösse.

Man findet sie oval oder rundlich, meist unregelmässig polygonal, oftmals in die Länge gezogen (Fig. 16,k k). Sie haben ähnlich wie Amylumkörner eine deutliche concentrische Schichtung welche sich um einen mehr oder weniger deutlichen Kern, der bei den langgezogenen Arten in zweifacher Zahl vorhanden sein kann (Fig. $16 \mathrm{k} \mathrm{k}_{1}$ ) herumlegt. Manchmal zeigen die Körperchen Interferenzerseheinungen, welche wohl durch die Schichtung bedingt wird. Sie lassen sich mit den meisten Farbstoffen gut tingiren. Ihre Grösse ist sehr verschieden, im Allgemeinen schwankt dieselbe zwischen 0,01323 und $0,0233 \mathrm{~mm}$.

Die chemischen Bestandtheile in diesen Körperchen müssen krystallinisch angeordnet sein, denn einige der grössten Körperchen liefern bei gekreuzten Nicols ein schwarzes Kreuz auf hellem Grunde als Beweis für ihre centralfaserige Structur.

1) Schiefferdecker l. c. p. 470-471.

2) P int ner l. c. p. 40.

3) P a g e n s t e ch er, Zur Naturg. der Cestoden. Zeitschr. f. w. Zool. Bd. XXX. 1878. p. 176.

4) v. $R \circ b \circ z$ l. c. p. 269. 
Was nun ibre chemische Zusammensetzung anbelangt, so nahm man immer an, dass die Körperchen im Wesentlichen aus Calciumcarbonat beständen, für Solenophorus trifft dies zu, das heisst, es wurde auf folgende Weise von mir nachgewiesen.

Zum Nachweis der Kohlensäure nahm ich vierzig 1/15 mm dicke Flächenschnitte bei einem Versuch, vier getrennte Proglottiden beim anderen Versuch.

Beide Objecte wurden in die Delle eines breiten Objectträgers gebracht und ein kleiner am Rande gut abgeschliffener und eingefetteter Glastrichter darüber gestiulpt. Die Trichterwand besitzt seitlich eine Oeffnung, durch welche mit Hülfe eines luftdicht schliessenden Gummistopfens ein gläsernes mit eingefettetem Hahn versehenes, am Ende ausgezogenes Trichterrohr führt. Der verengte Theil des umgestiulpten Trichters ist gebogen und in ein Kügelchen ausgeblasen. Nachdem letzteres mit Kalk-oder Barytwasser zur Hälfte angefïllt ist, manipulirt man bei ungestülpten Tricbter in der Weise weiter, dass man durch das Einfüllungsrohr bei geschlossenem Hahn etwas Acid. muriaticum (1:10) eingiesst. Dann wird der Hahn geöffuet und die Flüssigkeit fliesst aus dem pipettenförmigen Ende über die Objecte, dann schliesst man den Hahn wieder. Unter mit blossem Auge, besser mit der Linse wahrnehmbarem Brausen entweicht das Kohlendioxid und alsbald tritt eine dentliche weisse Trübung des Kalkwassers ein. Beistehender Holzschnitt versinulicht den Apparat.

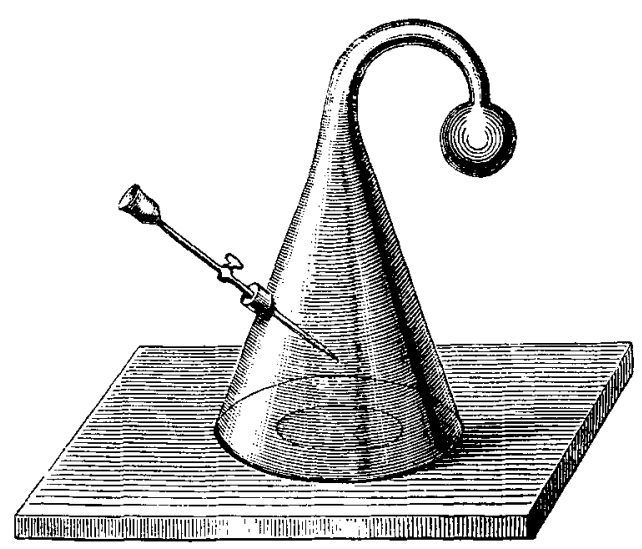

Man kommt übrigens auch mit weniger Glasbläserkünsten zum Ziel, indern man die umgebogene Trichterverengung direct in ein kleines Gefäss mit Kalkwasser tauchen lässt. Dass der Kohlendioxidgehalt der atmosphärischen Luft nicht in derselben Weise schnell einwirkt, kann man durch Controllversuche zeigen. Um sicher zu sein, dass die Kalkkörperchen selbst es sind, welche Kohlendioxyd bei Säurezusatz entweichen lassen, 
verfolgte ich die Gasentwicklung an einer Anzahl isolirter Körperchen unter dem Mikroskope. Dabei will ich gleich bemerken, dass verdünnte Salzsäure und Schwefelsäure die Körperchen nur theilweise, concentrirte Schwefelsäure sie aber ganz anflöst. Ich bin geneigt anzunehmen, dass der in verdünnten Säuren fast unlösliche Bestandtheil organischer Natur ist, ohne dass ich dabei an ein Stroma im Sinne von Sommer und Landois denke. Dann hätten wir in den Kalkkörperchen wohl ein Doppelsalz vor uns, vielleicht Calciumcarbonat - Calciumalbuminat, vielleicht neben dem Calciumearbonat Verbindungen aus der Harnsäuregruppe, welche ja einige Forscher für andere Cestoden nachgewiesen haben wollen. Dass oft durch die Flïssigkeit des Präparates etwas Kohlendioxyd absorbirt wird, wodurch eine geringere Gasentwicklung eintritt, ist sehr leicht möglich und Sommer's und Landois') Versuch unter der Luftpumpe spricht dafür. Noch wahrscheinlicher aber ist es, dass sich, wenn mit verdünnten Säuren gearbeitet wird, saures Carbonat bildet, welches nur in Lösungen bekannt ist und bei Einwirkung sehr verdünnter Säuren unzersetzt bleibt.

Auf einen Irrthum Sommer's und Landois' kann ich nicht umbin, hier hinzuweisen. Die genannten Forscher sprechen von einem Status nascens des Kohlendioxyds. •

Solcher Ausdruck ist nach unseren heutigen Ansichten uber die Constitution der Körper chemisch falsch.

Von einem Status nascendi kann man nur dann reden, wenn es sich um einfache gasförmige Radikale handelt, deren Atome noch nicht $\mathrm{zu}$ Molekïlen zusammengetreten sind.

Eine scheinbare Rechtfertigung konnte die Ausdrucksweise von Sommer und Landois erfahren, wenn wir uns den stattfindenden Process .- obgleich ich nach der Darstellung der genannten Autoren nicht annehmen kanu, dass dieselben soweit gedacht baben - folgendermassen vorstellen:

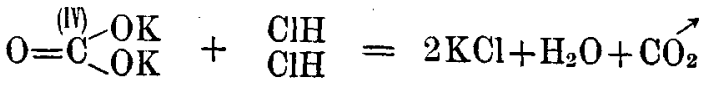

$$
\begin{aligned}
& \mathrm{O}=\mathrm{C}-\mathrm{OK} \quad \mathrm{ClH}
\end{aligned}
$$

Bei beginnendem Processe existirt noch nicht der gesättigte

1) Som mer und L and ois l. c. p. 46. 
Atomcomplex, i. e. das geschlossene Molekül Kohlendioxyd $\mathrm{Co}_{2}=$ $\mathrm{O}=\mathrm{C}=0$, sondern der mit zwei freien Valenzen behaftete, ungesättigte Rest: $\mathrm{O}=\mathrm{C}_{-}^{-\mathrm{O} \rightarrow}$

Derselbe würde alsdann die Rolle eines einfachen Radikales spielen. Aber selbst wenn diese Verhültnisse wirklich vorhanden wären, so würde der Ausdruck "Status nascens" seiner präcisen Definition gemäss, dennoch precär sein.

Dass nun wirklich Calcium ein Bestandtheil der in Rede stebenden Gebilde ist, babe ich in folgender Weise ermittelt.

Eine Anzahl Schnitte oder ganze Proglottiden wurden mit mässig verdünnter Salzsäure im Reagenzrohr einmal anfgekocht. Etwaiges Calicum musste alsdann als Calciumchlorid in der Fliissigkeit vorhanden sein. Da sich durch das Spectroskop noch $6 / 100000 \mathrm{mg}$ Culciumchlorid nachweisen lassen, so brachte ich einen Tropfen der auf dem Oelbade etwas eingedampften Lösung an die plattgeschlagene Schlinge eines feinen Platindrahtes. In den heissesten Theil einer Bunsen'schen Flamme gebracht verdampft die Fliissigkeit, als Leidenfrost'scher Tropfen, ohne zu kochen. Das Spectroskop zeigt weiter nichts als eine scharfe Natriumlinie; aber in dem Angenblicke, wo der letzte Flüssigkeitsantheil sich in Dampf verwandelt, blitzt im Spectrum momentan aber deutlich die characteristische griune Linie $\mathrm{Ca} \beta$, weniger deutlich die orangefarbene Linie Cac auf. Aber es gibt noch einen Nachweis, der nicht weniger empfindlich ist. Ein Tropfen der genannten Lösung wird anf den Objectträger gebracht, mit einem feinen Uhrgläschen als Deckglas bedeckt, und etwas verdünnte Schwefelsäure zugesetzt. Ein zweiter Tropfen wird in derselben Weise mit concentrirter Schwefelsäure vermischt; beide Präparate aberlässt man einige Zeit sich selbst'). Wenn Calcium vorhanden, so miissen jetzt Gypskrystalle entstehen, die unter dem Mikroskope erkennbar sind. Und in der That, es entstehen in beiden Präparaten die charakteristischen monoklinen Gypskrystalle (Fig. 17).

Bei Drehung zwischen gekreuzten Nicols aber verhalten sich die Krystalle aus verdïnnter Lösung anders als die aus concentrirter Lösung. Bei ersteren tritt nämlich Auslöschung parallel den

1) Man hüte sich die Krystallbildung durch Wärme beschleunigen zu wollen, die warme Flüssigkeit löst etwa gebildete Krystalle wieder auf. 
Kanten ein, letztere dagegen löschen schief aus. Controllversuche mit bekannter Substanz ergaben die Richtigkeit der Beobachtung.

Um sich zu überzengen, dass Calcium wirklich ein Bestandtheil der Körperchen selbst ist, wiederholt man die mikrokrystallinischen Versuche ${ }^{1}$ ) an einer Anzahl isolirter Körperchen. Es bedarf wohl kaum der Erwähnung, dass alle zur Verwendung gelangten Reagenzien erst auf ibre chemische Reinheit geprifft wurden.' Auf andere Bestandtheile als Calcium und Kohlendioxyd habe ich meine Untersuchungen der Kalkkörperchen bis jetzt nicht ausgedehnt.

Ich trete jetzt näher an die Fragen heran: Wo liegen die Kalkkörperchen und wie entstehen dieselben?

Bei Trematroden hat Claparède ${ }^{2}$ ) dieselben in beutelförmigen Endästen des Gefässsystems gesehen. Einen Zusammenhang der Kalkkörperchen mit dem Wassergefässsystem haben ferner Leuckart und Pagenstecher ${ }^{3}$ ) bei einem Echinobothrium gefunden, auch das gleichzeitige Auftreten der Kalkkörper bei der Anlage des Wassergefïsssystems im Kopfzapfen (vergl. Leuckart's Parasiten) spricht dafür. Andere und namentlich neuere der erwïhnten Forscher stellen nach eigenen Untersuchungen derartiges Verhalten in Abrede, so auch von $\mathrm{Roboz}^{4}$ ) für Solenophorus.

Ich babe im Laufe meiner Untersuchungen die Kalkkörperchen in den Lakunen (Fig. 3, 5, $11 \mathrm{k} \mathrm{k}$ ), in den Queranastomosen Fig. $918 \mathrm{k} \mathrm{k}$ ), und in den in die Lakunen übergehenden Abzweigungen (Fig. $11 \mathrm{k} \mathrm{k}_{1}$ ), sowie in den Geweben, (Fig. $11 \mathrm{k} \mathrm{k}_{11}$, Fig. $2 \mathrm{kk}$, Fig. $3 \mathrm{k}_{11}$ ) gefunden. Die lakunären Räume dicht unter der Cuticula cnthalten oft eine grosse Anzahl derselben, und auf Flächenschnitten durch die Cuticula gelangen die Körperchen bäufig mit in den Schnitt (Fig. $10 \mathrm{k} \mathrm{k}$ ). Im Allgemeinen ist die Menge der Kalkconcremente bei Solenophorus eine viel kleinere als bei anderen, namentlich menschlichen Cestoden.

Die Fig. 18 repräsentirt ein bei 400facher Vergrösserung mit

1) Ich fühle mich verpflichtet, an dieser Stelle öffentlich nochmals Ferrn Dr. L e hma n $n$ in Mülhausen meinen Dank zu sagen für die Freundlichkeit, mit welcher er mir seine Apparate zur Disposition stellte.

2) Cla pa rè d e, Ueher die Kalkkörperchen der Trematoden und die Gattung der Tetracotyle in Zeitschr. f. w. Zool. Bd. IX. p. 99.

3) Vergl. L e u c kart, Parasiten. p. 175.

4) v. Roboz l. c. p. 270. 
dem Zeichenapparate angefertigtes Bild einer Queranastomose der Längsstämme. Man síeht die Körper deutlich in dem Lumen des Kanales liegen, eine Täuschung ist nicht möglich.

Ich glaube somit nicht, dass die Kalkkörperchen urspriinglich dem Gewebe angehören und nacb Vircbow's und Anderer Meinung verkalkte Bindesubstanzzellen sind - ich muss nach meinen Untersuchungen und gelungenen Präparaten entgegen den von Virchow, Sommer und Lando is und Anderen ausgesprochenen Ansichten in den Kalkkörperchen vielmehr mit $\mathrm{Cl}$ a p a rè de ein mit dem Gefässsystem in innigster Beziehung stehendes Analogon einer Skeletbildung erblicken, welche dem Organismus zum Schutze gereichen soll.

Und in der That, man findet an denjenigen Körperpartien, welche einerseits am zartesten gebaut, andererseits den Einflüssen der Magen- und Darmausscheidungen am meisten ausgesetzt sind, die zahlreichen Kalkkörperchen geradezu einen Panzer bilden.

Dicht anter der Cuticula sowohl in den Lakunen als aucb in der Bindesubstanz und dem Protoplasmamantel, in welche sie von den Lakunen aus eindringen, findet man sie reichlich angehäuft, während sie in der Mittelschicht spärlicher auftreten. Die subenticularen Lagen der Saugnäpfe, ja iberhaupt der ganze Scolex sind so reichlich mit Kalksubstanz versehen, dass dünne Quersehnitte sich mit Jodgrïn violett färben, indem durch die Kalksubstanz ans dem Farbstoff die Basis in Freiheit gesetzt wird. In den letzten Proglottiden findet man auf dem Querschnitte auch in den Längsgefässen eine körnige Masse (Fig. 19ek, ik), die auf Sïurezusatz aufbranst. Diese Masse besteht aus den Resten zertrümmerter Kalkkörperchen, welche durch die Mündung der Wassergefässe aus dem Körper entfernt werden. Der Befund der Concremente in dem Gefässapparate lässt ïber ihre Entstehung keinen Zweifel aufkommen. Aus der in die Leibeshöhle aufgenommenen Ernährungsflüssigkeit würden mit Hülfe der (Wimper?)-Trichter und der als einzellige Drüsen fungirenden Plasmazellen vor deren Eingang Abscheidungsprocesse vor sich gehen, deren Prodncte durch die capillaren Zuführungsröhrchen in die Wassergefässlängsstämme gelangen, wo dieselben sich vielleicht unter Verbindung mit Substanzen, welche die grossen im Gallertgewebe, nabe den Gefässen gelegenen, von mir als Drisen in Anspruch genommenen, Zellen excerniren, in deren Protoplasma man, wie erwälnt, ähnlich wie ich das ron 
den Zellen des Bojanus'schen Organes beschrieben '), feste Concremente findet, zu den fertigen Kalkkörperchen umbilden.

Wenn, wie ich nachwies, auch Calciumcarbonat ein wesentlicher Bestandtheil der in Rede stehenden Gebilde ist, so ist dadurch nicht ausgeschlossen, dass auch stickstoffhaltige organische Verbindungen aus der Harnsïuregruppe darin enthalten sein können, wofür einmal der directe Nachweis bei anderen Cestoden, sodann die Schwerlöslichkeit selbst in concentrirten Säuren spricht, dann repräsentirt das Wassergefäss system der Cestoden, wie diese ja auch längst angenonmmen wird, eine Niere und ist analog den Segmentalorganen und dem Bojanus'schen Organ, welches in letzter Zeit von K ollma n $n^{2}$ ) selbst als Segmentalorgan betrachtet wird. Ob die genannten Organe auch Homologa sind, kann bei dem augenblick. licben Stande der Entwicklungsgeschichte nicht festgestellt werden

Es darf uns nicht wundern, wenn wir stickstoff haltige Zersetzungsproducte zum Aufbau eines Panzers verwendet and tiberall im Körper abgelagert finden; denn dieselben sind in den Kalkkörperchen als unlösliche Verbindungen enthalten.

Die Concremente welche zur Panzerbildung verwendet werden sollen, gelangen aus den in die Lakunen mïndenden Gefässästen in das Lakunensystem, und vertheilen sich so im ganzen Körper, wobei die heftigen Muskelcontractionen Hülfe leisten. Der Ueberschuss an Material wird durch die Hauptstämme abgefiihrt, wie daraus ersichtlich ist, dass das Ende derselben oft ganz mit Trümmern der Concremente, an denen man manchmal nocb die Schichtung wahrnimmt, vollgepfiopft ist (Fig. 19).

\section{Mnsknlatur.}

Ich bespreche die Muskeln der Proglottiden und die Muskulatur der Bothridien.

„Entsprechend dem allgemeinen Plane, welcher in der Muskulatur der Cestoden ausgeprïgt ist, verlaufen die Muskeln bei Solenophorus in der Proglottis nach drei verschiedenen Richtungen." Dicht unter Cuticula, mit den, "elastischen Fasern"derselben eine Netzfigur bildend, verläuft, wie auch von Roboz ${ }^{3}$ ) angiebt, eine Lage glatter Längsmuskelfasern ( $F i g . ~ 1,2$ n. $10 \mathrm{slm}$ ), wie sie

1) Griesbach, Ueber den Bau des Bojanus'schen Organes etc. Arch. f. Naturg. 1877.

2) Koll ma n n, Ueber Verbindungen zwischen Coelom $u$. Nephridium.

3) v. Roboz l. c. p. 271. 
zuerst von Stied $a^{1}$ ) bei Bothriocephalus latus aufgefuuden wurde. In jüngeren Gliedern füllen diese Längsmuskeln einen grossen Theil der sogenannten Rindenschicht aus, wïhrend sie in älteren Gliedern spärlicher werden. An mit 30\% Kalicansticumlösung isolirten subcuticularen Muskelfasern erkennt man ihre langspindelförmige Gestalt. Ihre Länge beträgt dann 0,8123 bis $0,8174 \mathrm{~mm}$, ihre grösste Breite misst $0,014 \mathrm{~mm}$. Weder Essigsäure noch irgend einen der Kerne schön färbenden Anilinfarben Laben mir einen Kern gezeigt, auch die in der Längsrichtung verlaufende fibrilläre Streifung, welche von Roboz (a.a. O.) beschreibt und abbildet, ist mir nachzuweisen nicht gelungen. Dichotomische Theilung der Spindelpole wie Sommer und Lando is ${ }^{2}$ ) bei Botbriocephalus, Schiefferdecker ${ }^{3}$ ) bei Taenia beschreiben ${ }^{4}$ ), sowie gelegentliche Anastomosen ${ }^{5}$ zwischen den Spindeln sind mir auch zu Gesichte gekommen (Fig. 20).

Die Ringmuskulatur bildet, wenn man von einer Rinden- und Mittelschicht reden will, ungeführ die Grenze zwischen beiden, sie bildet um die Mittelschicht herum einen geschlossenen, $0,05 \mathrm{~mm}$ dicken Ring (Fig. 1. 3. $8.19 \mathrm{rm}$ ), Musculi transversi“ imSinne der Sc hi e fferdecker'schen Beschreibung und Abbildung (Taf. XVI Fig. 1a), ,die sich an den schmalen Seiten des Bandwurmgliedes leicht fächerförmig ausbreiten", kann ich bei Solenophorus nicht auffinden. Dagegen findet Sehiefferdecker nirgends Ringmuskeln. Endlich gibt es noch solche Muskeln, welche von der dorsalen zur ventralen Fliiche des Gliedes, also vertikal zur Körperaxe verlaufen. Diese dorsoventralen Muskelfasern bilden natirlich nicht etwa eine besondere Schicht, sondern ziehen als zerstreute Bündel oder einzelne oftmals sehr feine Fasern von beträchtlicher Länge, bald geradezu senkrecht zur Körperlängsachse, bald mehr oder weniger zu ihr geneigt durch das ganze Körperparenchym (Fig. 1, 3, 9, d v m). Diese Muskeln heften sich, wie schon erwähnt mit einer Art Sehne an die Cuticula (Fig. $1 \mathrm{dvms}$ ). Quergestreifte Muskelfasern, sowie die von Pintner beschriebenen Myoblasten finde ich bei Solenophorus nirgends.

1) Stied a 1. c. p. 180.

2) Som mer und Landois 1. c. p. 43.

3) Schieferdecker 1. c. p. 472.

4) Siehe auch $\mathrm{M}$ i not an Turbellarien. Arb. d. zool. Institutes. Würzburg Bd. III. p. 447.

5) Vergl. auch Steudener 1. c. p. 281. 
Die complicirte Einrichtung des Muskelapparates bei Tetrarbynchus ist zum Theil wohl der Riisselvorrichtung zuzuschreiben. Von einer Nevenendigung in den glatten Muskelfasern, wie von Roboz (1. c. pag. 271) sie beschreibt, konnte ich nichts entdecken. Was dic Muskulatur in dem Scolex anbetrifft, so kann ich die Beobachtungen, welche Kabane ${ }^{1}$ ) an Taenia perfoliata gemacht, für Solenophorus bestätigen. Es gibt auch hier radiär zum Lumen des Saugnapfes verlaufende Muskeln, welche zusammen mit der Ringmuskelschicht, welche das Saugnapflumen umgibt, in einer Ebene verlaufend die bekannte ,irisartige" Zeichnung bilden. Die subcuticularen Längsmuskelfasern finden sich im Scolex auch, wic man auf Querschnitten deutlich wahrnimmt. Dagegen kommt eine peripherische Ringmuskelschicht bei Solenophorus nicht vor, auch entdecke ich keine Spur von dem „muskulösen Zapfen" welchen Kahane bei Taenia perfoliata beschreibt und abbildet (Taf. VIII, Fig. 5).

\section{Nervensystem.}

Bis za den schönen Untersuchungen Lang's ${ }^{1}$ ) an Tetrarhynchus und der Erweiterung derselben durch andere Forscher hielt man das Vorkommen eines Nervensystems bei den Cestoden noch nicht mit Sicherbeit fïr erwiesen. Noch im Jahre 1877 wurde von Minot in seinen Studien an Turbellarien und von $\mathrm{Halley}$ in seinem 1879 veröffentlichten Werke: Contributions à l'histoire naturelle des Turbellariés ein Nervensystem den Pathelminthen abgesprochen, wahrend Graff der Planaria Limuli (Zool. Anz. 1879) ein solches zuerkennt.

Hente ist die Existenz eines Nervensystems bei den Cestoden ausser allem Zweifel gestellt. Gleichzeitig mit Lang's Untersuchungen erschienen die ron Pintner (1. c.), nach denen das Nerrensysten von Tetrarbynchus longicollis (l. c. pag. 72 Taf. V, Fig. 15, 10 etc.) aus einer glatten nach hinten spitz zulaufenden

1) Ka hane, Anatomie von Taenia perfoliata als Beitrag zur Kenntniss der Cestoden. Zeitschr. f. wissensch. Zool. 1880. Bd. XXXIV. p. $175 \mathrm{sq}$.

2) La n g, Das Nervensystem der Cestoden im Allgemeinen und dasjenige der Tetrarchynchen im Besonderen in: Mittheilungen aus der zool. Station zu Neapel. Bd. II. H. 3. 1881. - id. Untersuchungen zur vergl. Anat. u. Histologie des Nervensystems der Plathelminthen. ibid. Bd. III. H. 1 u. 2. 1882. 
krippenförmigen Masse von Ganglienzellen besteht, die in einer membranösen Hülle mit anliegenden gekernten Muskelfasern eingeschlossen ist. Dorsal und ventral von dieser zwischen den Haftscheiben lagernden Gehirnmasse finden sich je zwei Nervenstämme, von denen sich zunächst in der Höhe des Gebirns die zwei dorsalen untereinander und ebenso die zwei ventralen durch je eine Querkommissur verbinden, worauf sich jederseits die beiden Stämme einer Körperseite verbinden, um sich jedoch sofort wieder in vier Stämme zu trennen; so entstebt ein Nervenring, der die Ganglienmasse umläuft. Die beiden äusseren der vier nun in eine Reihe getretenen Nervenstränge verlaufen zwischen den Wassergefässen im Aussenparenchym bis zum Kopfende, nach rechts und links gleich weit von einander entfernte Querästchen abgebend; die beiden inneren verlaufen in Innenparenchym und theilen sich in vier an die Muskelwalzen des Rüsselapparates herantretende Stämme, die mit räthselhaften, gallertartigen und zelligen Elementen in Verbindung stehen. Zuletzt bat von Roboz (a. a. O.) bei Solenophorus ein Nervensystem gefunden, aber seine Untersuchungen sind nicht erschöpfend. In den folgenden eigenen Beobachtungen möchte ich zunächst das Nerrensystem des Scolex, dann das der Strobila betrachten.

Wenn Wagener ${ }^{1}$ ) im Scolex von Tetrarchynchus ein Ganglion beschreibt - und aus den Untersuchungen Lang's ${ }^{2}$ ) geht hervor, dass er richtig gesehen hat - wenn van Beneden ${ }^{3}$ ) an demselben Thier eine ganze Gruppe von Ganglien auffindet, wenn Schneider ${ }^{4}$ ) im Kopfe von Ligulaarten und Taenia perfoliata eine Nervencommissur erkennt, wenn Blumberg ${ }^{5}$ ) bei drei Tänien aus dem Darm des Pferdes im Kopfe eine unbestimmte Anzahl von Ganglien, deutlich sichtbar aber zwci Ganglienhaufen existiren lässt, wenn Steudener ${ }^{6}$ ) bei mehreren Cestoden in der Höhe der

1) W a g n er, Enthelm. Diss' inaug. Acta Acad. L. C. 1. Bd. XXIV. Suppl. - id. Naturkund. Verhandlingen von de hollandsche Mantschapp d. Weetensch. etc.

2) Lang l. c.

3) J. P. v. Beneden l. c.

4) Sehneider l. c.

5) Bl u mberg, Ein Beitrag zur Anatomie von Taenia plicata, perfoliata, mamillana in: Arch. f. wissenschaftl, u. praktische Thierheilkunde. Bd. III. 1877.

6) Steudener 1. c. 
Saugnäpfe deutlich eine Nervenanastomose gesehen hat, Zog $\operatorname{raf}^{1}$ ) und $\mathrm{Kahane} \mathrm{e}^{2}$ ) solehe Angaben bestätigen und endlich $\nabla$ on $\mathrm{Roboz}^{3}$ ) eine $0,045 \mathrm{~mm}$ breite Quercommissur bei Solenophorus als Nervencentrum beschreibt and abbildet, so muss ich für Solenophorus folgendes behaupten: Ein Theil des centralen Nervensystems befindet sich in der Mitte des Scolex, in der Scheidewand, welche die beiden Bothridien trennt. Daselbst sieht man auf dem Querschnitte 4 Ganglien, welche mit einander ein Kreuz bilden (Fig. 21, $\mathrm{g} \mathrm{g}_{1}$ ) aber nicht so, dass alle vier in eine Ebene fielen, sondern zwei, gerade in der Mitte zwischen den Bothridien(Fig.21g) liegen tiefer, als die anderen beiden, welche bis fast an die Saugnäpfe geriickt sind (Fig. $21 \mathrm{~g}_{1}$ ); die letzteren wïrden wohl mit den von Blanchard ${ }^{4}$ ) beschriebenen Sangnapfganglien zu identificiren sein. Von dieser Lagendifferenz der Ganglien tiberzeugt man sich an geeigneten Querschnitten durch verschiedene Tubuseinstellung. Fig. 21 gibt in halbschematischer Weise eine Ansicht des Nervensystems in einem Querschnitt durch den Scolex. Man sieht die Ganglien auf dem Querschnitt mehr oder weniger rund. Der Durchmesser der median gelegenen Ganglien (Fig. $21 \mathrm{~g})$ beträgt $0,075 \mathrm{~mm}$, der der an den Saugnäpfen liegenden $0,059 \mathrm{~mm}$. Die Ganglien, bestehen aus ziemlich grossen, aus feingekörntem Plasma gebildeten uni- und bipolaren Zellen (Fig. $22 \mathrm{ub}$ ), (tripolare, wie von Roboz (l. c. pag. 277) zu sehen glaubte, habe ich mit Sicherheit nicht finden können), oft fehlen die Ausläufer ganz und die Zellen erscheinen alsdann gleichmässig rund (Fig. 22r). Eine von den runden Zellen, denen, wie den übrigen, eine eigene Membran fehlt, besitzt den Durchmesser von $0,012 \mathrm{~mm}$. Der Kern, oft mit dentlichem Kernkörperchen, misst $0,00476 \mathrm{~mm}$ und färbt sich mit denjenigen Azofarbstoffen, die überhaupt gute Kernfärbungen geben, sowie mit Jodgriin und Hämotoxylin intensiv und distinct, während das Plasma die Farbstoffe diffus oder gar nicht annimmt. Die Nervenknoten sind von dem umgebenden Gallertgewebe durch eine sehr zarte, das Licht stark brechende, Farbstoffe nur schwer annehmende Hülle umgeben (Fig. $23 \mathrm{gh}$ ), an der ich, wie Blumberg (pag. 42) es beschreibt, eine streifige Structur nicht erkennen

1) $\mathrm{Z}$ ograf l. c.

2) $\mathrm{Kahanel}$. c.

3) von Roboz l. c. p. 277.

4) Blanchard, Recherches sur l'organisation des Vers Annales des sciences naturelles. III Série. Tom X. 1848. 
konnte, and welche ich wiederum als eine dem Gallertgewebe entstammende structurlose Membran betrachte.

Alle Ganglien sind durch Commissuren verbunden. Die tiefgelegenen 2 Ganglien werden durch eine Commissur verbunden, welche sich achtförmig um dieselben herumschlingt (Fig. $21 \mathrm{ac}$ ). Bei Fig. 23 sieht man ein Stück dieser Commissur aus dem Ganglion entspringen. Von jedem dieser tiefliegenden Ganglien verlaufen dann Commissuren (Fig. $21 \mathrm{~s} \mathrm{c}$ ), welche zwischen 0,0124 und $0,0155 \mathrm{~mm}$ breit sind, zu den an die Saugnäpfe gerückten zwei Ganglien - ein Stück einer solchen auch bei Fig. 23 i c sichtbar und diese beiden werden unter sich wieder durch eine mächtige, an der breitesten Stelle $0,1128 \mathrm{~mm}$ messende Commissur (Fig. $21 \mathrm{bc}$, Fig. 24) verbunden, welche sich wie eine Brüicke über die 8 förmige Verbindung hinüberschlägt. Diese Commissur sowie auch die beiden tiefer gelegenen medianen Ganglien hat schon von Roboz gesehen, der iibrige Theil scheint ihm entgangen. Dieses ganze Gangliensystem, sowobl die Nervenknoten als auch die Commissuren bilden bei Solenophorus das schön entwickelte Centralorgan des Scolex. Am deutlichsten sichtbar treten die Ganglienzellen in der breiten briickenartigen Commissur (Fig. 24) hervor, in derselben tritt die Form der einfachen Rundzelle mehr zurück und Zellen mit Fortsätzen, uni- oder bipolar sind hänfiger. Eine solche Ganglienzelle misst mit ihrer längsten Axe $0,011 \mathrm{~mm}$. Der dentliche mit einem Kernkörperchen versehene Kern ist $0,0028 \mathrm{~mm}$, der Ausläufer $0,033 \mathrm{~mm}$ gross.

Alle 4 Ganglien entsenden peripherische Nervenäste, an welchen ich eine weitere Differenzirung nicht wahrnehmen konnte. Von den tief gelegenen medianen Ganglien verläuft jederseits ein starker Nerv (Fig. 21 n), welcher sich um den betreffenden Saugnapf ringförmig herumzulegen scheint, doch gelang es mir immer nur die Anfänge dieses vermeintlichen Nervenringes zu sehen. Es wäre dieser Ring wohl der durch von Roboz (a. a. O.) beschriebene. Ich glaube aber, dass bald nach dem Ursprung aus den Ganglien, diese Nervenfaser ihre compacte Beschaffenheit verliert, um sich in lauter feine Aeste aufzulösen, welche die Saugnäpfe versehen. Sicher ist ein derartiges Verhalten bei den peripherischen Nerven, welche den höher und seitlich gelegenen Ganglien entspringen (Fig. $21 \mathbf{n}_{\mathbf{t}}$ ). Ans ihnen treten nämlich viele Zweige aus, welche mit anfangs gröberen, endlich kaum noch wahrnehmbaren Ver- 
zweigungen den ganzen Scolex durchziehen. In diesen peripherischen Theilen habe ich keine Ganglienzellen finden können. Ein sehr übersichtliches Bild von dem gesammten Nervensystem des Scolex erhält man, wenn dünne Schnitte mit Rose bengale oder Azofarbstoffen gefärbt werden. Besondere Nervenendapparate in der Cuticula, wie Blumenberg (l.c.pg. 45) sie gesehen hat, gibt es nach meinen Untersuchungen bei Solenophorus nicht. Schneider und Kahane kommen in ihren Arbeiten auf die Homologisirung des Centralnervensystems der Cestoden mit dem anderer Thiere zu sprechen, Kahane hält es noch für verfriht, hieriber Vergleiche anzastellen, hält aber die Deutung Schneider's für ganz plausibel. Ich bin weit davon entfernt hier nähere Betrachtungen und Gedanken über derartige Homologisirung zu äussern, möchte mich derselben vielmehr, trotz der geistreichen Hypothese Schneider's, für Solenophorus enthalten. Der zweite Theil des Nervensystems besteht in zwei aus den tiefer gelegenen medianen Ganglien des Scolex entspringenden Längsstämmen, welche nach aussen zu von den Wassergefässen (Fig. 25), also dem Proglottidenrande näher gerïckt durch die ganze Strobila verlaufen. Anf dem Querschnitt ist es oft schwer den Seitennerv zu erkennen, denn er hebt sich nur undeutlich von dem umgebenden Gewebe ab. Fig. 25 repräsentirt einen Schnitt, in welchem der Seitennerv s n seinen weitesten Abstand von den Wassergefässen besitzt.

Mit Sicherheit haben zuerst Sommer und Land 0 is ${ }^{1}$ ) die Nervenstränge der Strobila gesehen, doch glaubten sie es in diesen Gebilden bei Botbriocephalus mit Gefässen zu thun zu haben, anch

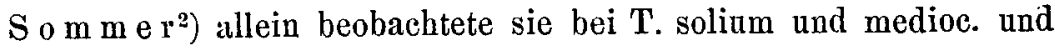
beschrieb sie unter dem Namen plasmatisches Gefïssnetz als Circulationsorgan für eine Nutritionsfliissigkeit.

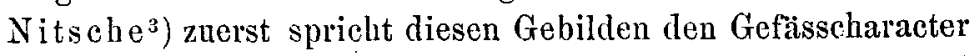
ab, vermuthet in ihnen ein neues bisher iibersehenes Organ und

1) Sommer und Landois 1. c. p. 12 .

2) Sommer, Ueber den Bau und die Entwicklung der Geschlechtsorgane bei Taenia medioc. u. solium. Zeitschr. f. w. Zool. Bd. 34. H. 3.

3) Nitscho: Untersuchungen über den Bau der Taenien. Zeitschrift f. w. Zool. Bd. XXIII. 
nennt sie „spongiöse Stränge". Erst $\mathrm{S}$ e h n e id e $\mathbf{r}^{\text {l) }}$ zeigt, dass in diesen Strängen ein Theil des Nervensystems zu suchen sei, als welchen man sie seitdem betrachtet. Tasehenberg $\mathrm{g}^{2}$ ) hat später die Identität der Nerven mit den spongiösen Strängen für die Trematoden erkannt. Der Verlauf dieser Stränge bei Solenophorus ist wie auch von $\mathrm{Roboz}^{3}$ ) bei demselben Cestoden und die übrigen Forscher, welche darüber bei anderen Vertretern Untersuchungen anstellten, beschreiben, ein mehr oder weniger wellenförmiger, was daraus hervorgeht, dass man auf Querschnitten diese Seitenstränge bald den Wassergefässlumina näher, bald weiter von ihnen entfernt liegen sieht, dass sie selbst aber nicht etwa Wassergefässe repräsentiren, wie noch $\mathrm{P}$ oiri e ${ }^{4}$ ) glaubte, dessen Irrthum ibrigens schon von $\mathrm{M}$ o n i e $z^{5}$ ) berichtigt wurde, geht daraus hervor, dass man, wie auch schon v o $\mathrm{n}$ o b oz angibt, deutliche Ganglienzellen in ihnen findet. Diese sind meist bipolar und stark spindelförmig in die Länge gezogen. Fig. 26 gibt einen Längsschnitt durch den Seitennerven, bei $\mathrm{g}$ die Ganglienzellen.

Schiefferdecker ${ }^{6}$ ) lässt bei Taenia jederseits drei solcher Nervenstränge durch die Strobila hinziehen, was auch S teuden er ${ }^{7}$ ) für einzelne grössere Taenien behauptet. Anastomosen in den einzelnen Proglottiden finde ich mit Ste udener ${ }^{8}$ ) nicht. Doch konnte ich mich davon iiberzengen, dass sie, wie von Roboz angibt, feine Nervenäste entsenden (Fig. 25n a) iber deren Ende ich nichts berichten kann. Was nun die histiologische Structur dieser Nervenstränge anbelangt, so stimmen darin meine Beobachtungen mit von Roboz's im Allgemeinen überein. Sie entbehren, wie auch $\mathrm{Kahane}^{9}$ ) von T. perfol. behauptet, einer selbständigen Hülle, be-

1) $\mathrm{Schneider}$ l. c. p. 34 .

2) T a sche n berg, Beiträge zur Kenntniss ectoparasitischer, mariner Trematoden. Halle 1879.

3) v. Roboz l. c. p. 278.

4) Po ir i e r: Sur l'appareil excréteur du Solenophorus megalocephalus Compt. rend. 1878. p. 1013 sq.

5) M o n i z , Sur quelques points d'organisation du Solenophorus megalocephalus. Bulletin scientif. des Dep. du Nord. 2. Série. p 113 sq.

6) $S \mathrm{ch}$ iefferdecker l. c. p. 474.

7) Steudener l. c. p. 293.

8) id. 1. c. p. 293.

9) Ka bane l. c. p. 246 . 
stehen aus ungemein zarten Fasern und deutlichen, wenn auch in geringerer Zahl als in den Scolex-Ganglien und -Commissuren, vorhandenen Ganglienzellen, auf welche die oben gegebene Beschreibung passt. Von einem besonderen Stiitzgewebe findet sich bei Solenophorus im. Umkreis der Stränge nichts.

Alles das, was Schiefferdecker ${ }^{1}$ ) als bisher unbekannten peripherischen Theil des Nervensystems in der Strobila von T. solium beschreibt, die Nervenendapparate motorischen und sensiblen Characters ete. finde ich bei Solenophorus nicht, glaube aber, wie sehon erwähnt mit $P$ intner, dass diese Endapparate nicbts als die Wassergefässtrichter nebst Zubehör gewesen sind. Aus allen diesen Betrachtungen geht hervor, dass der hier besprochene Cestode ein deutlich entwickeltes Nervensystem mit centralen und peripherischen Abschnitten besitzt. In Anbetracht dessen, dass die seitlichen Nervenstränge Ganglienzellen führen, wie sie in den Ganglien und Commissuren des Scolex auch sich finden, bin ich mit Kahane der Ansicht, auch diese Gebilde dem centralen Abschnitte zuzurechnen und halte die Auslegung derselben als ein noch undifferenzirtes Bauchmark für recht annehmbar.

Ich schliesse meine Untersuchungen vorläufig hier ab. Ueber die Geschlechtsorgane behalte ich mir vor, an dem Reste des noch vorhandenen Materials, wenn ausreichend, ein andermal zu berichten.

Aus vorstehender Arbeit ergibt sich für Solenophorus megalocephalus folgendes:

\section{Résumé.}

1) Im Körper existirt nur eine einzige Art von Bindesubstanz und diese ist das Gallertgewebe, in welchem sich miteinander anastomosirende lakunäre Hohlräume befinden.

2) Die Körperorgane sind von strueturlosen Membranen, den Abkömmlingen dès Gallertgewebes umhüllt.

3) Die sogenannte Cuticula; besser Körperwand oder Grenzmembran ist weder epithelialer noch bindegewebiger Natur, sondern eine Bildung des Gallertgewebes.

4) Die bisher unter dem Namen subcuticulare Zellenlagen

1) Schiefferdecker l. c. p. $477 \mathrm{sq}$. 
beschriebenen Gebilde repräsentiren weder eine Matrix, noch Bindegewebszellen, sondern sind lebendiges Protoplasma und sind, was Beschaffenheit und Function anbelangt, dem Plasmaleibe gewisser Protozoen vergleichbar.

5) Das sogenannte Wassergefässsystem besteht aus zwei stärkeren und zwei schwächeren durch die ganze Strobila verlaufenden Kanälen. Dieselben treten in gleicher Stärke in den Scolex ein und umlaufen, mit häufiger Inselbildung, schlingenförmig: die Bothridien. Ring- oder Queranastomosen im Scolex finden sich nicht. Die in der Strobila mit stärkerem Lumen ausgestatteten Längskanäle besitzen in jeder Proglottide Queranastomosen, sowie Abzweigungen, welche in das Lakunensystem des Gallertgewebes übergehen.

Die schwächeren Längskanäle der Strobila enden nicht blind, münden auch nicht in die stärkeren Kanäle ein. Eine allmähliche Bildung eines Poras excretorius findet nicht Statt. Ein oberflächliches Gefässsystem im Sinne der Autoren existirt nicht.

6) Der für die Körperbeschaffenheit gebrauchte Ausdruck „parenchymatös“ ist, mit Riicksicht auf die im ganzen Leibe sich findenden Lakunen, unpassend.

7) Das Lakunensystem repräsentirt die Leibeshöhle.

8) In dieser Leibeshöhle, nach der Körperperipherie an Hänfigkeit zunehmend, liegen trichterartige Gebilde, als Anfang des sogenannten Wassergefässsystems.

9) Das in den Gefässen enthaltene Liquidum fliesst von den Trichtern aus centripetal, durch feine, Capillaren ähnliche, iiberall gleich weite, vielfach mit einander communicirende Röbrchen, welche meist deltaförmig in die Längskanäle der Strobila und in die Schlingen des Scolex einmïnden.

10) Im ganzen Körper finden sich, demselben gewissermaassen als Panzer dienend, zum Theil aus Calciumcarbonat bestehende Concremente; dieselben sind nicht verkalkte Zellen, sondern werden, vielleicht mit Hülfe besonderer einzelliger Drïsen, in dem Wassergefässsystem gebildet. Zugleich besitzt das Wassergefässsystem noch die Function eines Harnapparates.

10) Die Muskulatur besteht im Wesentlichen aus Längs-, Ringund dorsoventralen Muskeln.

11) Ein Nervensystem ist vorhanden, dasselbe besteht im Scolex aus vier Ganglien, welche durch Commissuren verbunden 
sind, und peripherische Nerven an die Bothridien abgeben. Durch die ganze Strobila ziehen nach aussen zu von den Wassergefässen zwei Nervenstränge, an welchen Commissuren nicht zur Beobachtung gelangten.

B a s e 1, März 1883.

\section{Eklärung der Tafeln XXI, XII und XXIII.}

Fig. 1. Theil eines mit dem Mikrotom angefertigten $1 / 4 \mathrm{~mm}$ dicken Querschnittes durch eine Proglottide aus der Mitte der Strobila. Tinction mit Rose bengale und Jodgrün. Aufhellung mit Anisöl. Balsameinschluss Engelbert und Hensoldt Syst. 5. (Imm.) Oc. I.

$\mathbf{m}=$ sogenannte Cuticula.

$\mathrm{m}_{1}=$ Schicht "elastischer" Fảsern.

$z m=$ Ansatz der dorso-ventralen Mnskeln beim Schnitt zerfasert. dvms = Sehnen der dorso-ventralen Muskeln.

$\mathrm{dvm}=$ dorso-ventrale Muskeln.

$\mathrm{rm}=$ Ringmuskelschicht, im Schnitt schief getroffen.

slm = subcuticulare Längsmuskeln.

ggw = Gallertgewebe.

$\mathrm{pm}=$ Protoplasmamantel.

pmk $=$ Kerne desselben.

$\mathrm{k}=$ isolirte Kerne im Gallertgewebe.

$k_{1}=$ Kerne mit spärlicher Plasmazone daselbst.

$1=$ Lacunen.

dst $=$ Dotterstock.

Fig. 2. Schnitt wie Fig. 1. Osmiumsäure, Anisöl, Balsameinschluss. Hartnack: Homogene Imm. Nr.2. Ocul. 3 Ausgezogener Tubus. Künstliche Beleuchtung. Abbé'scher Condensor.

$\mathrm{kk}=$ Kalkkörperchen.

Die übrige Bezeichnung wie Fig. 1.

Fig. 3. Querschnitt durch eine Proglottide in der Mitte der Strobila. Engelbert und Hensoldt Syst. 5. Imm. Oc. 1.

at $=$ abgebrochener Trichter.

$\mathrm{t}=$ Trichter.

tk = Kerne der vor dem Trichter gelagerten Zellen.

cgf $=$ Capillargefässe der Trichter. 
$\Delta=$ deltaförmige Einmündung derselben in das starke Längsgefäss ik. stml $=$ structurlose Membran.

spz - Spindelzellen.

$\mathrm{gfb}=$ Gallertfibrillen.

$\mathrm{d} z=$ Drüsenzelle mit Conerementen.

$\mathbf{k k}_{\text {, }}=$ Kalkkörperchen des Gallertgewebes.

Die übrige Bezeichnung wie vorher.

Fig. 4. Häutung der Cuticula. Querschnitt. Engelbert und Hensoldt Syst. 2. 0c. 3.

$f^{\prime}=$ abgestossene Schüppchen.

Die äbrige Bezeichnung wie vorher.

Fig. 5. Lakunen und Trichter nebst Zubehör aus einem Querschnitt. Engelbert und Hensoldt Syst. 5. Imm. Oc. 3.

$\mathbf{k p t}=$ Ueberrest der vor dem Trichter gelagerten Plasmazelle.

$\mathrm{p}=$ Wimperplatte (?) in Hohlraume des Trichters.

tk, = Kern aus der dem Trichter vorgelagerten Plasmazelle allein in der Lacune zurïckgeblieben.

Die übrige Bezeichnung wie früher.

Fig. 6. Theile des Gallertgewebes. Engelbert und Hensoldt Syst. 5. Imm. Oc. 3 .

$\mathrm{a}=$ Spindelzellen.

$\mathrm{b}=$ Gallertfibrillen.

$\mathrm{dz}=$ Concremente führende Drüsenzellen.

Fig. 7. Querschnitt durch die sogenannte Cuticula. Engelbert und Hensold t Syst. 5. Imm. Oc. 3 .

$\mathrm{pk}=$ Porenkanäle.

$\mathrm{ca}=$ Borsten und Haare der Cuticula.

pg = Pigment im Gallertgewebe.

Die übrige Bezeichnung wie vorher.

Fig. 8. Querschnitt durch eine Proglottide ungefähr in der Mitte der Strobila. Tinction mit Jodgrün. Engel bert und Hensoldt Syst. 0. Oc. 2.

df $=$ dorsale Fläche.

vf $=$ ventrale Fläche.

ek $=$ äusserer Wassergefässlängskanal.

$\mathrm{ik}=$ innerer Wassergefässlängskanal.

Die übrige Bezeichnung wie vorher.

Fig. 9. Querschnitt durch den hinteren Abschnitt einer Proglottide ungefähr aus der Mitte der Strobila. Tinction mit Crocein (Friedrich Bayer \& Co., Anilinfarbenfabrik, Elberfeld ${ }^{1}$ ). Secretan (Paris). Syst 1. Oc. 2. eingeschobener Tubus.

1) Vergl. auch Griesbach, Die Azofarbstoffe als Tinctionsmittel für menschliche und thierische Gewebe Dieses Archiv Bd. XXII. 
Fig. 9a. Quercommissur zwischen den inneren Längsgefüssen.

ia = Inselbildender Ast.

Fig. 10. Flächenschnitt durch die sogenanute Cuticula. Tinction mit Jodgrün. Engelbert und Hensoldt Syst. 5. Imm. Oc. 2. ef $=$ „elastische“ Fasern der Cuticula.

Die übrige Bezeichnung wie vorher.

Fig. 11. Querschnitt durch den hinteren Abschnitt einer Proglottide aus der Nitte der Strobila. Engelber t und Hensold t Syst. 4. Oc. 1.

$\mathrm{la}=$ in das Lacunensystem übergehender Ast des inneren Längskanales.

Die übrige Bezeichnung wie vorher.

Fig. 12. Querschnitt durch den Halsabschnitt, um die gleich starken Wassergefässe zu zeigen. Engelbert und Hensoldt Syst. 2. Oc. 0.

Fig. 13. Scolex, defectes Präparat. Wassergefässschlingen mit Berliner Blau injicirt. Engelbert und Hensoldt Syst. O. Oc. 1. Buzeichnung siehe im Texte.

Fig. 14. Querschnitt durch den Scolex. Engelbert und Hensoldt Syst. 4 Oc. 0 .

$\mathrm{gf}=$ durchschnittene Gefässpartien.

Fig. 15. Querschnitt durch dẹ äusseren Längskanal aus einer Proglottide nahe dem Ende der Strobila. Eugelbert und Hensoldt Syst. 5 Imm. Oc. 1. Bezeichnung wie vorher.

Fig. 15. Verschiedene Formen von Kalkkörperchen. Engelbert und Hensoldt Syst. 4. Oc. 1.

Fig. 17. Gypskrystalle.

Fig. 18. Querschnitt durch ein Stück einer Queranastomose aus einer Proglottide nahe dem Ende der Strobila. Engelbert.und Hensoldt Syst. 4. Oc. 0. Mit Zeichenapparat angefertigt. Bezeichnung wie vorher.

Fig. 19. Querschnitt durch eine Proglottille ganz am Ende der Strobila. Engelbert und Hensoldt. Syst. 2. Oc. 2. Die Längskanäle sind mit Trümmern von Kalkkörperchen angefüllt. Die Bezeichnung wie vorher.

Fig. 20. Isolirte subcuticulare Längsmuskelfasern. Engelbert und Hensoldt Syst. 5. Imm. Oc. 1 .

Fig. 21. Querschnitt durch den Scolex. Tinction mit Rose bengale. Engelbert und Hens old t Syst. 4. Oc. 2, aber halbschematisch.

$\mathrm{g}=$ median gelegene Ganglien.

$\mathrm{g}$, = Saugnapfganglien.

ac $=$ achtförmige Commissur.

sc $=$ Seitencommissuren.

$\mathrm{bc}=$ Brückencommissur.

$\mathbf{n}=$ Nervenast aus den medianen Ganglien.

$\mathrm{n},=$ Nerven aus den Saugnapfganglion. 
Fig. 22. Ganglienzellen. Kerntinction mit Hïmatoxylin und Jodgrün. Engelbert und Hensoldt Syst. V. Imm. Oc. 2.

$\mathrm{n}=$ unipolare

$\left.\begin{array}{l}\mathrm{r}=\text { runde } \\ \mathrm{b}=\text { bipolare }\end{array}\right\}$ Zellen.

Fig. 23. Theil eines mit dem Mikrotom aus dem Scolex entnommenen Querschnittes. Eng elbert und $\mathrm{H}$ en sold t. Syst. 5. Imm. Oc. 2 . $\mathrm{gh}=$ Ganglionhülle.

Die übrige Bezeichnung wie vorher.

Fig. 24. Brückencommissur. E $\mathrm{ng}$ e $\mathrm{lb}$ e $\mathrm{rt}$ und $\mathrm{H}$ e n s o l d t Syst. 5. Imm. Oc. 2.

Fig. 25. Querschnitt durch den hinteren Abschnitt einer Proglottide aus der Mitte der Strobila. Engelbert und Hen sold t Syst. 4. Oc. 2. $\mathrm{sn}=$ Seitennerv.

Die übrige Bezeichnung wie vorher.

Fig. 26. Längsschnitt durch den Seitennerven.

$\mathrm{g}=$ Ganglienzelle.

$\mathrm{na}=$ ausgetretener Nervenast.

(Aus dem anatomischen Institute zu Breslau.)

\section{Die Plattenmodellirmethode}

von

Dr. G. Boru.

Als ich im Jahr 1876 die Entwicklung der Nasenhöhle und des Thränennasengangs der Amphibien an Schnittserien studirte, machte mir die Schwierigkeit, die complicirten Schnittfiguren der Organe der Ethmoidalgegend im Kopfe wieder zu einem richtigen, plastischen Bilde zusammenzusetzen so sehr zi schaffen, dass ich auf die Idee kam, diese Reconstruction, die die Pbantasie nach Maass und Zabl nur sehr unvollkommen zu leisten vermochte, objectiv mittelst Zusammenlegen in Fläche und Dicke gleichmässig vergrösserter 